\title{
Review Article \\ Influence of Acute and Chronic Exercise on Glucose Uptake
}

\author{
Martin Röhling, ${ }^{1,2}$ Christian Herder, ${ }^{1,2}$ Theodor Stemper, ${ }^{3}$ and Karsten Müssig ${ }^{1,2,4}$ \\ ${ }^{1}$ Institute for Clinical Diabetology, German Diabetes Center, Leibniz Center for Diabetes Research, \\ Heinrich Heine University Düsseldorf, 40225 Düsseldorf, Germany \\ ${ }^{2}$ German Center for Diabetes Research (DZD), Munich, 85764 Neuherberg, Germany \\ ${ }^{3}$ Department Fitness and Health, University Wuppertal, 42119 Wuppertal, Germany \\ ${ }^{4}$ Department of Endocrinology and Diabetology, Medical Faculty, Heinrich Heine University Düsseldorf, 40225 Düsseldorf, Germany
}

Correspondence should be addressed to Karsten Müssig; karsten.muessig@ddz.uni-duesseldorf.de

Received 23 November 2015; Revised 31 January 2016; Accepted 3 February 2016

Academic Editor: Thomas J. Hawke

Copyright (C) 2016 Martin Röhling et al. This is an open access article distributed under the Creative Commons Attribution License, which permits unrestricted use, distribution, and reproduction in any medium, provided the original work is properly cited.

Insulin resistance plays a key role in the development of type 2 diabetes. It arises from a combination of genetic predisposition and environmental and lifestyle factors including lack of physical exercise and poor nutrition habits. The increased risk of type 2 diabetes is molecularly based on defects in insulin signaling, insulin secretion, and inflammation. The present review aims to give an overview on the molecular mechanisms underlying the uptake of glucose and related signaling pathways after acute and chronic exercise. Physical exercise, as crucial part in the prevention and treatment of diabetes, has marked acute and chronic effects on glucose disposal and related inflammatory signaling pathways. Exercise can stimulate molecular signaling pathways leading to glucose transport into the cell. Furthermore, physical exercise has the potential to modulate inflammatory processes by affecting specific inflammatory signaling pathways which can interfere with signaling pathways of the glucose uptake. The intensity of physical training appears to be the primary determinant of the degree of metabolic improvement modulating the molecular signaling pathways in a dose-response pattern, whereas training modality seems to have a secondary role.

\section{Introduction}

Insulin resistance plays a key role in the development of type 2 diabetes and is caused by genetic predisposition and environmental and lifestyle factors including physical inactivity and poor nutrition habits [1]. These risk factors also contribute to obesity, which is a major determinant of glucometabolic impairment and systemic subclinical inflammation [2]. Physical activity, as cornerstone in the prevention and treatment of diabetes, has marked acute and chronic effects on the regulation of glucose uptake and on inflammatory processes $[3,4]$. The glucometabolic impairment in type 2 diabetes results from alterations of different signaling pathways modulating glucose uptake comprising insulin- and exercise-induced signaling pathways. However, during exercise, glucose uptake is normal or near normal [5], pointing to an insulin-independent activation of relevant signaling pathways mediating exercise-induced glucose uptake. An insulin-resistant state is also associated with changes in immunological and hormonal cross talk involving interleukin 6 (IL-6), tumor necrosis factor alpha $(\mathrm{TNF}-\alpha)$, or adiponectin. These cytokines and adipokines are part of inflammatory processes and immune defense and can also affect molecular signaling pathways modulating glucose uptake. Behavioral interventions as well as unstructured physical activity have been shown to positively influence inflammatory processes, which was accompanied by improvements in glucose uptake $[6,7]$.

Physical exercise is distinguished primarily in resistance training and endurance training. Endurance training imposes a high-frequency (repetition), low-power output demand on muscular contraction, whereas resistance exercise imposes a low-frequency, high-resistance demand [8]. These two traditional modalities can also be performed as high-intensity training (HIT). This training form comprises alternating cycles of intensive and extensive phases involving endurance training, also known as high-intensity interval training (HIIT), and resistance training or the supramaximal exercise form of sprint interval training (SIT) $[9,10]$. 
The overarching aim of this review is to summarize the mechanisms and molecular signaling pathways mediating glucose uptake as well as related changes in the release of immune mediators upon acute and chronic exercise exposure. Furthermore, we aim to assess the role of training intensity and training modality for the modulation of the aforementioned processes.

\section{Search Strategy and Evaluation of Data}

We searched PubMed/MEDLINE without language restriction from database inception until January 20, 2016, using the following search terms: "signaling OR pathway OR GLUT4 OR glucose OR inflammation OR inflammatory OR cytokine" AND "exercise OR training OR endurance exercise OR resistance exercise OR contraction". Reference lists of review articles and all included articles identified by the search were also examined for other potentially eligible studies. The search was limited to human and animal studies. Duplicates were removed. Search results for relevant intervention studies are summarized in Table 1 and shown in detail in Tables 2, 3, 4, and 5 .

The current literature does not provide a clear definition for acute or chronic effects of training [11]. The training effect is influenced by the time period between termination of the last bout of exercise and measurement as well as by training intensity [4]. Measurements of training effects within a time period of $0-72 \mathrm{~h}$ after exercise termination can show acute effects, even in a chronic training process, which makes it difficult to distinguish between acute and chronic training effects. In this review, we define the effect of chronic training as the sum of all training sessions, according to previous work [4].

\section{Effect of Exercise on Molecular Signaling Cascades}

3.1. Insulin Receptor Substrate 1 (IRS-1)/Phosphatidylinositol 3-Kinase (PI3-K) and Akt/Protein Kinase B (Akt/PKB) Pathways. In conditions of rest, insulin regulates glucose transport into the muscle due to activation of a protein signaling cascade. After binding of insulin to its receptor, the insulin receptor is autophosphorylated. Insulin receptor substrate 1 (IRS-1) binds to the phosphorylated tyrosine residues of the insulin receptor and is subsequently phosphorylated by the tyrosine kinase of the insulin receptor. Binding of IRS-1 to the p85 subunit of phosphatidylinositol 3-kinase (PI3-K) results in activation of a PI3-K-dependent pathway comprising phosphoinositide-dependent kinase (PDK) and atypical protein kinase $\mathrm{C}(\alpha \mathrm{PKC})$ [110]. Key downstream molecules modulating translocation of glucose transporter type 4 (GLUT4) to the plasma membrane comprise, besides Akt/protein kinase B (Akt/PKB), Ras-related C3 botulinum toxin substrate 1 (Racl), the TBC1 domain family member 1 (TBC1D1), or the Akt substrate of $160 \mathrm{kDa}$ (AS160) [32, 110, 111] (Figure 1).

In type 2 diabetes patients, despite a normal amount of GLUT4 transporters [112], insulin fails, in general, to induce adequate insulin signaling as assessed by IRS-1 tyrosine phosphorylation, Akt/PKB activity, and translocation of GLUT4 to the cell membrane [113-116].

Exercise activates the insulin-signaling pathways, facilitating GLUT4 expression and translocation to the cell membrane. The effects of acute and chronic exercise on glucose uptake and insulin signaling are shown in Table 1.

Acute continuous endurance exercise with 45-60 min of training at $65-75 \%$ of maximum oxygen consumption $\left(\mathrm{VO}_{2 \max }\right)$ leads to higher rates of tyrosine phosphorylation of insulin receptor and IRS-1/2 and to increased activity of PI3$\mathrm{K}$ in muscle of untrained healthy as well as insulin-resistant individuals [12-15]. In contrast, short and light resistance with 5 sets of 8 repetitions of isokinetic leg extension shows no effect in endurance trained athletes [16] (Table 2). Furthermore, acute muscle contraction activates molecules of the distal insulin signaling which are known to be involved in GLUT4 translocation such as Racl, AS160, and TBC1D1 $[16,47,48]$ which will be described in more detail below. Recent animal studies have shown that only very intense muscle contraction in situ via sciatic nerve stimulation of multiple muscle types with $2-5 \mathrm{~V}$ as well as one bout of intense swimming for $120 \mathrm{~min}$ or $60 \mathrm{~min}$ of running with a speed of $22 \mathrm{~m} / \mathrm{min}$ and incline of $10 \%$ led to an acute increase in phosphorylation and activity of key molecules like the different AKT isoforms (AKT-1, AKT-2, and AKT-3) and AS160 [49-51] (Table 3).

In contrast to these studies, some human as well as animal studies reported no effect of acute exercise on proximal insulin signaling like changes in insulin receptor amount, IRS-1 phosphorylation, or PI3-K activity [16-21]. In the study of Wojaszewski et al. [21], one-legged cycling exercise for 60 min at intensity of $18-23 \%$ of $\mathrm{VO}_{2 \max }$ was not sufficient to induce changes in proximal insulin signaling in young trained individuals. Furthermore, $60 \mathrm{~min}$ of cycling at $75 \% \mathrm{VO}_{2 \max }$ did not lead to changes in proximal signaling in untrained and obese individuals $[19,20]$. In line with this, some animal studies found that a running speed of $18 \mathrm{~m} / \mathrm{min}$ for $45 \mathrm{~min}$ as well as electrical stimulation with $1-3 \mathrm{~V}$ were also not sufficient to induce insulin signaling in skeletal muscle [17, 18].

The reason for these discrepant results in human and animal studies might lie in the differences in the intensity of training conditions in acute exercise. Moderate endurance exercise seems to acutely increase proximal signaling in untrained individuals $[12,13,15]$, whereas short and light resistance and endurance training in trained individuals shows no effect $[16,21]$ (Tables 2 and 3 ). In addition, the time point after exercise when the effect of exercise is studied appears to be highly important. A recent review from Frøsig and Richter identified a critical time point of 3 to $4 \mathrm{~h}$ after exercise for exercise-induced increase in glucose uptake indicating a time-dependent course in the activation of exercise induced molecular signaling [22], which may be the reason for the unaltered signaling in measurements 16 and $24 \mathrm{~h}$ after exercise termination $[19,20]$. Though training intensity and the time point of investigation appear to be important for exercise-induced activation of insulin signaling, there is still a lack of knowledge about the underlying mechanisms of 
TABLE 1: Effect of acute and chronic exercise on molecular signaling pathways.

\begin{tabular}{|c|c|c|c|c|}
\hline Metabolic factor & $\begin{array}{l}\text { Acute } \\
\text { training }\end{array}$ & $\begin{array}{l}\text { Chronic } \\
\text { training }\end{array}$ & $\begin{array}{l}\text { Exercise characteristics (intensity, } \\
\text { modality) }\end{array}$ & References \\
\hline $\begin{array}{l}\text { Proximal insulin signaling } \\
\text { (IRS-1, PI3-K, PDK, } \alpha \text { PKC) }\end{array}$ & $\uparrow^{*}$ & $\uparrow \uparrow$ & $\begin{array}{c}\text { Moderate-to-intensive exercise for } \\
\text { untrained and high-intensity exercise } \\
\text { for trained individuals, independent of } \\
\text { modality }\end{array}$ & {$[12-22]$} \\
\hline AMPK & $\uparrow \uparrow$ & $\uparrow \uparrow$ & $\begin{array}{l}\text { Dose-response pattern, independent of } \\
\text { modality }\end{array}$ & {$[8,23-31]$} \\
\hline $\mathrm{Ca}^{2+}$-calmodulin axis & $\uparrow \uparrow$ & $\uparrow \uparrow$ & $\begin{array}{l}\text { Dose-response pattern, independent of } \\
\text { modality }\end{array}$ & {$[8,27,31-35]$} \\
\hline mTOR/S6K & $\uparrow \uparrow$ & $\uparrow \uparrow$ & $\begin{array}{l}\text { Dose-response pattern, independent of } \\
\text { modality }\end{array}$ & {$[29,36-46]$} \\
\hline $\begin{array}{l}\text { Downstream targets: } \\
\text { AS160, TBC1D1, Rac1 }\end{array}$ & $\uparrow$ & $\uparrow$ & $\begin{array}{c}\text { Dose-response pattern for AS160 and } \\
\text { Racl, independent of modality }\end{array}$ & {$[16,47-60]$} \\
\hline IKK/NF- $\kappa \mathrm{B}$ pathway & $\uparrow \uparrow^{\$}$ & $\downarrow \downarrow$ & $\begin{array}{l}\text { Dose-response pattern, independent of } \\
\text { modality } \\
\end{array}$ & {$[2,61-77]$} \\
\hline Inflammasome pathway & - & $\downarrow \downarrow$ & $\begin{array}{l}\text { Dose-response pattern, independent of } \\
\text { modality }\end{array}$ & {$[2,78-80]$} \\
\hline JNK/MAPK pathway & $\uparrow \uparrow$ & $\downarrow \downarrow$ & $\begin{array}{l}\text { Dose-response pattern, independent of } \\
\text { modality } \\
\end{array}$ & {$[67-69,81-85]$} \\
\hline Adiponectin & $\uparrow$ & $\uparrow$ & $\begin{array}{c}\text { Intense exercise, independent of } \\
\text { modality }\end{array}$ & {$[3,5,53,86-94]$} \\
\hline
\end{tabular}

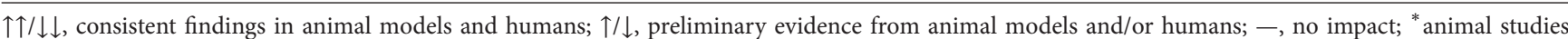
showed no effects; ${ }^{\$}$ increase in skeletal muscle and increase/decrease in adipose tissue; $\alpha$ PKC, atypical PKC; AMPK, AMP-activated protein kinase; AS160, Akt substrate of $160 \mathrm{kDa}$; Ca, calcium; CaMKII, $\mathrm{Ca}^{2+} /$ calmodulin-dependent protein kinase 2 ; IRS-1, insulin receptor substrate 1; IKK/NF- $\kappa \mathrm{B}$, I $\kappa \mathrm{B}$ kinase/nuclear factor kappa B; JNK, C-Jun N-terminal kinase; MAPK, mitogen-activated protein kinases; mTOR/S6K, mammalian target of rapamycin/ribosomal S6 kinase; PDK, phosphoinositide-dependent kinase; PI3-K, phosphoinositide 3-kinase; Racl, ras-related C3 botulinum toxin substrate 1; TBC1D1, TBC1 domain family member 1 .

acute exercise and effects of different training factors, such as modality and intensity, on insulin signaling.

Chronic exercise can also lead to higher rates of tyrosine phosphorylation of key molecules in the insulin signaling cascade in muscle of healthy as well as insulin-resistant individuals $[52,95,96]$. A recent exercise study observed enhanced whole-body insulin action and increased Akt and AS160 phosphorylation after 10 weeks of chronic resistance training with exercises for upper and lower body and running endurance training in untrained individuals [52] indicating an independence of exercise modality. Compared to untrained controls, trained humans show increased insulin-stimulated PI3-kinase activation. The positive association between PI3-kinase activation and endurance capacity $\left(\mathrm{VO}_{2 \max }\right)$ indicates that regular exercise leads to greater insulin-stimulated IRS-1-associated PI3-kinase activation in human skeletal muscle [14]. This is in line with recent animal studies showing that intense chronic endurance training in mice with a running speed of $20-32 \mathrm{~m} / \mathrm{min}$ on a treadmill increases total AS160 phosphorylation [53].

3.2. AMPK Signaling Pathway. AMPK is a metabolic master switch regulating several intracellular systems and consists of two catalytic alpha-isoforms: $\alpha 2$ - and $\alpha 1$-AMPK. AMPK is activated by phosphorylation by kinases such as liver kinase B1 (LKB1) [117] and is regulated by cellular energy demand.
Increasing adenosine monophosphate/adenosine triphosphate (AMP/ATP) and creatine/phosphocreatine ( $\mathrm{Cr} / \mathrm{PCr})$ ratios, reflecting for instance the glucose deprivation state [118], are important stimuli for AMPK activity. In line with this, activation of AMPK is positively associated with an increased skeletal muscle glucose uptake [23].

In obese diabetic and nondiabetic humans, exerciseinduced stimulation of the AMPK activity is attenuated but can be fully activated by exercise with higher intensities of training as compared to healthy lean controls [24, 25]. Acute cycling endurance exercise at a moderate intensity of $50-70 \%$ of $\mathrm{VO}_{2 \max }$ increased AMPK activity and resulted in a 2.7fold increase in mRNA expression of AMPK $\alpha 1$ and AMPK $\alpha 2$ $[24,25]$.

Activation of AMPK by acute cycling exercise led to an enhanced glucose uptake in human skeletal muscle [26]. AMPK phosphorylation and activity showed an intensitydependent response pattern. More intense $\left(80 \%\right.$ of $\left.\mathrm{VO}_{2 \max }\right)$ acute cycling endurance exercise with the same amount of energy expenditure $(400 \mathrm{kcal})$ resulted in a higher activation of signal transduction compared to less intense $\left(40 \% \mathrm{VO}_{2 \max }\right)$ endurance exercise [27]. High-intensity interval training consisting of repeated sessions of intense work like all-out sprints for $30 \mathrm{sec}$ (SIT) induces, with a minimum of effort $(<80 \mathrm{~kJ}$ total), an increased phosphorylation of AMPK. Though this kind of training appears to mimic resistance exercise because of the intense, short-term muscle work, phosphorylation and activity of downstream targets linked to hypertrophy like 


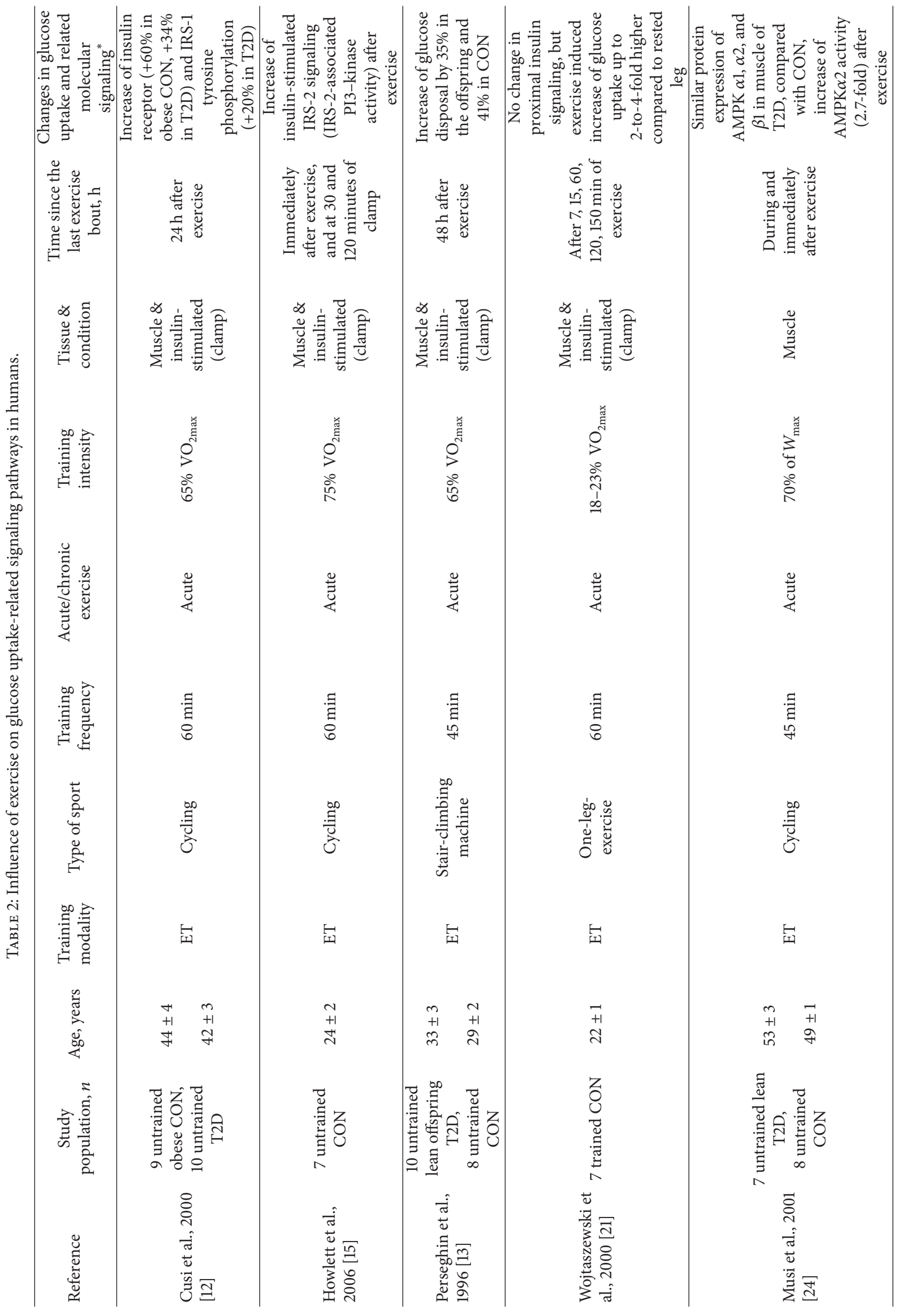




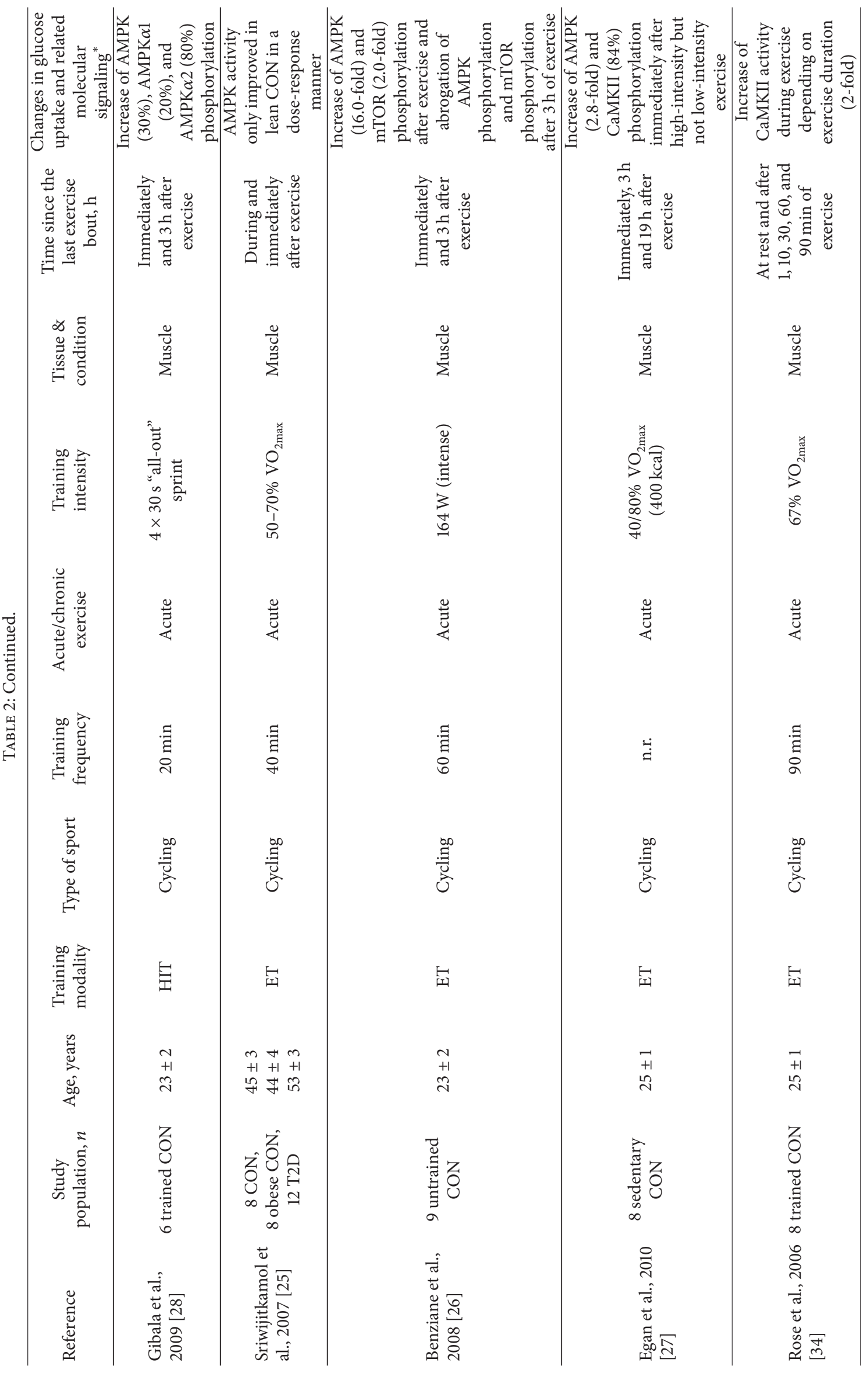




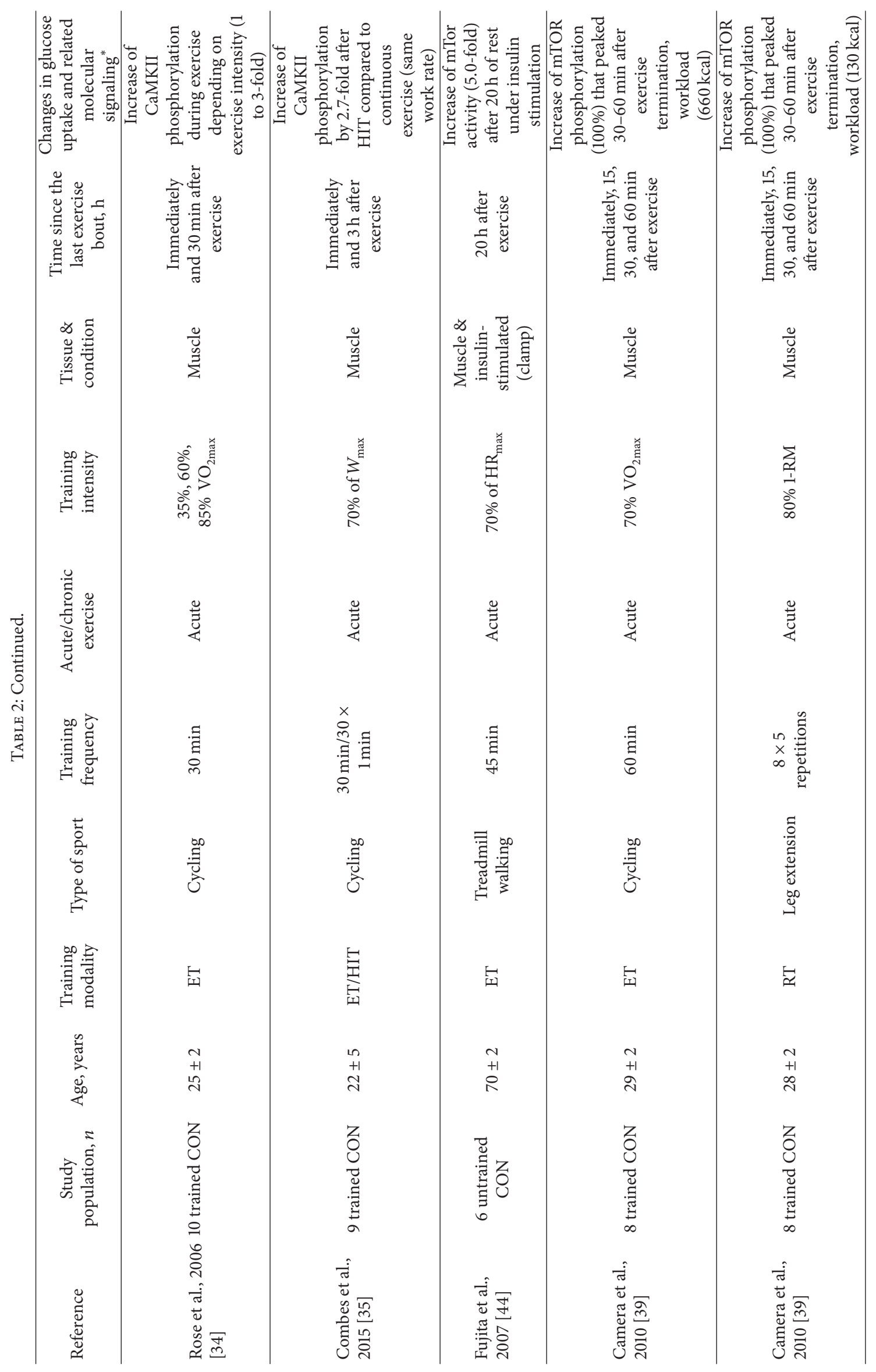




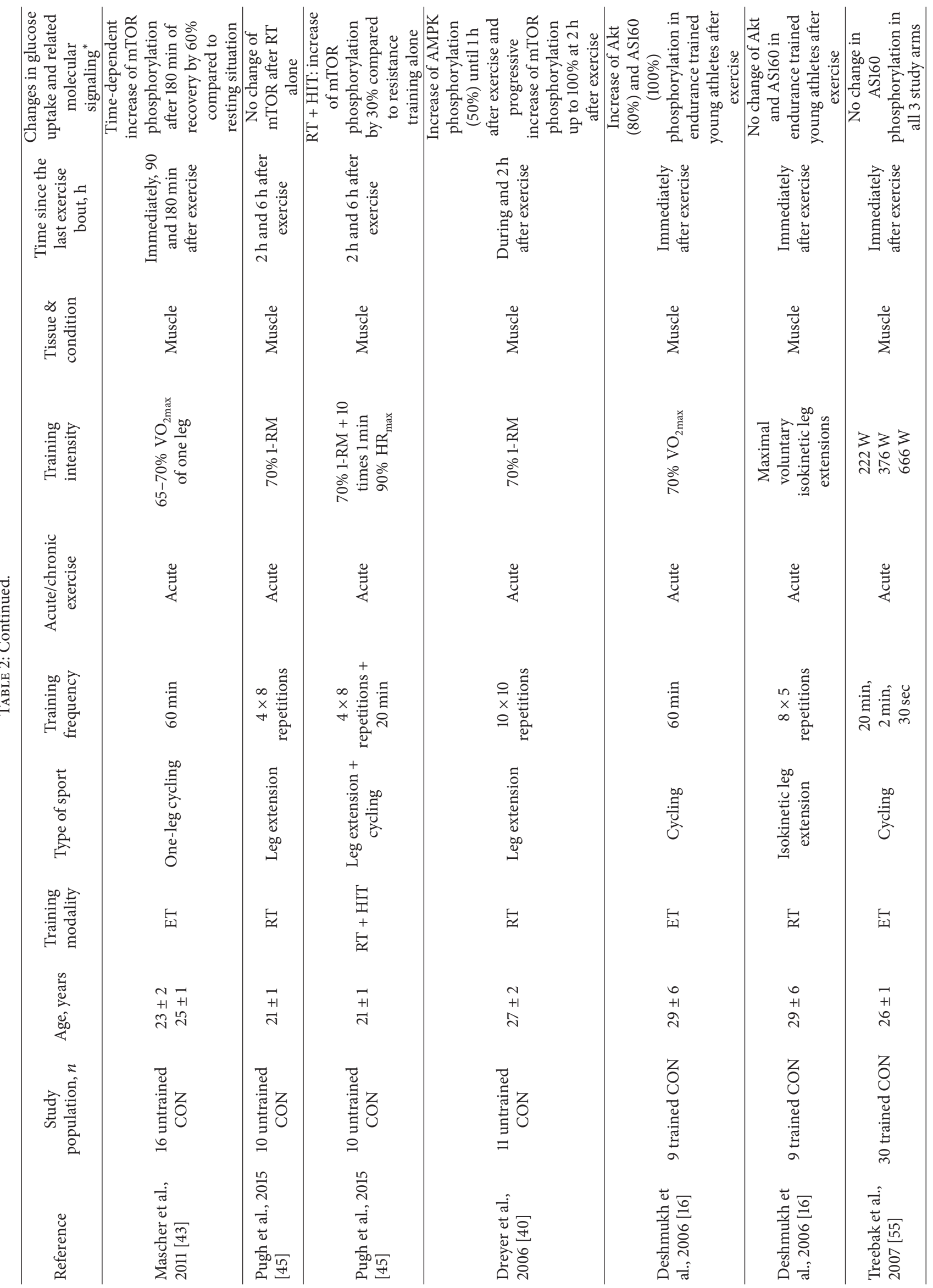




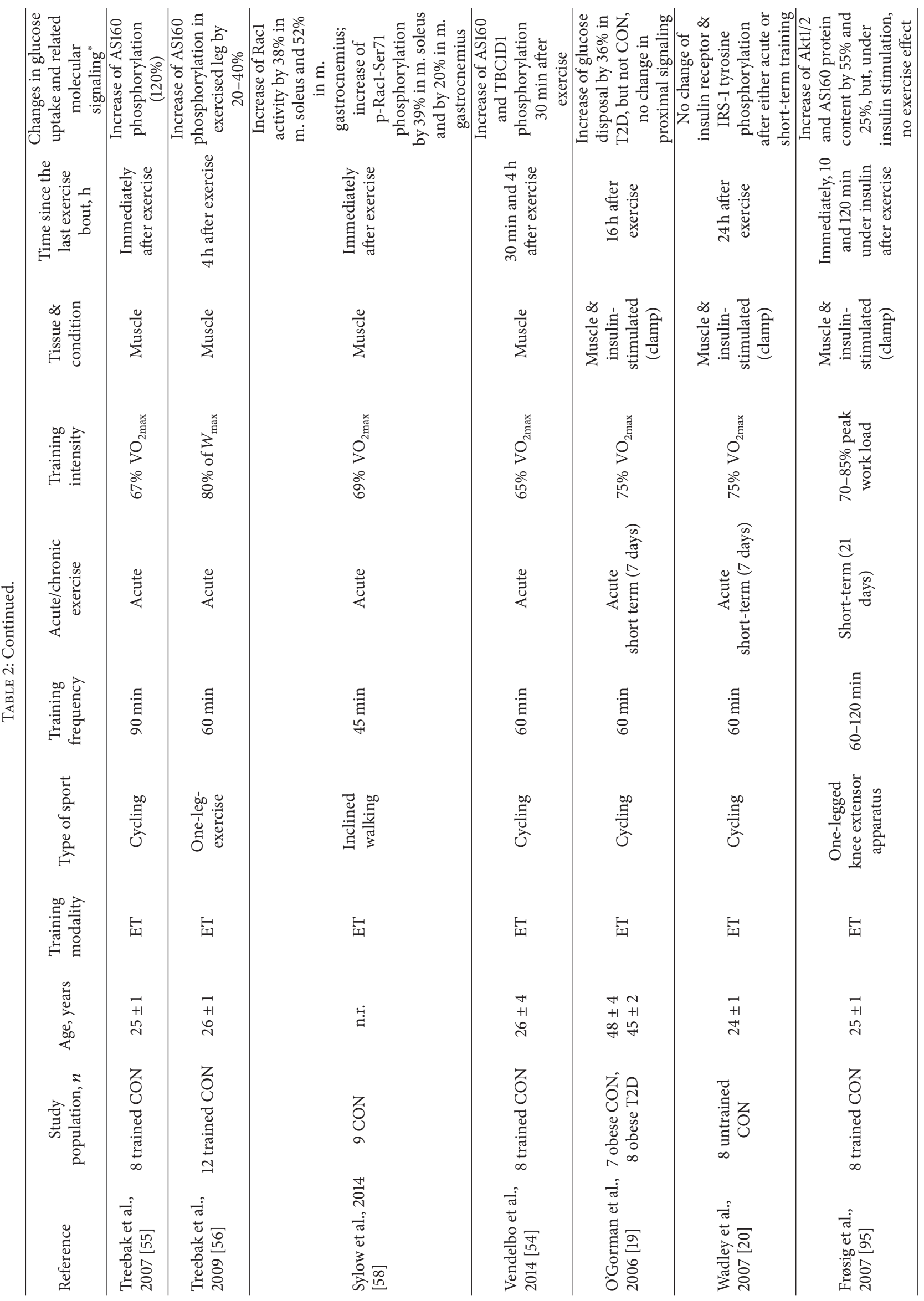




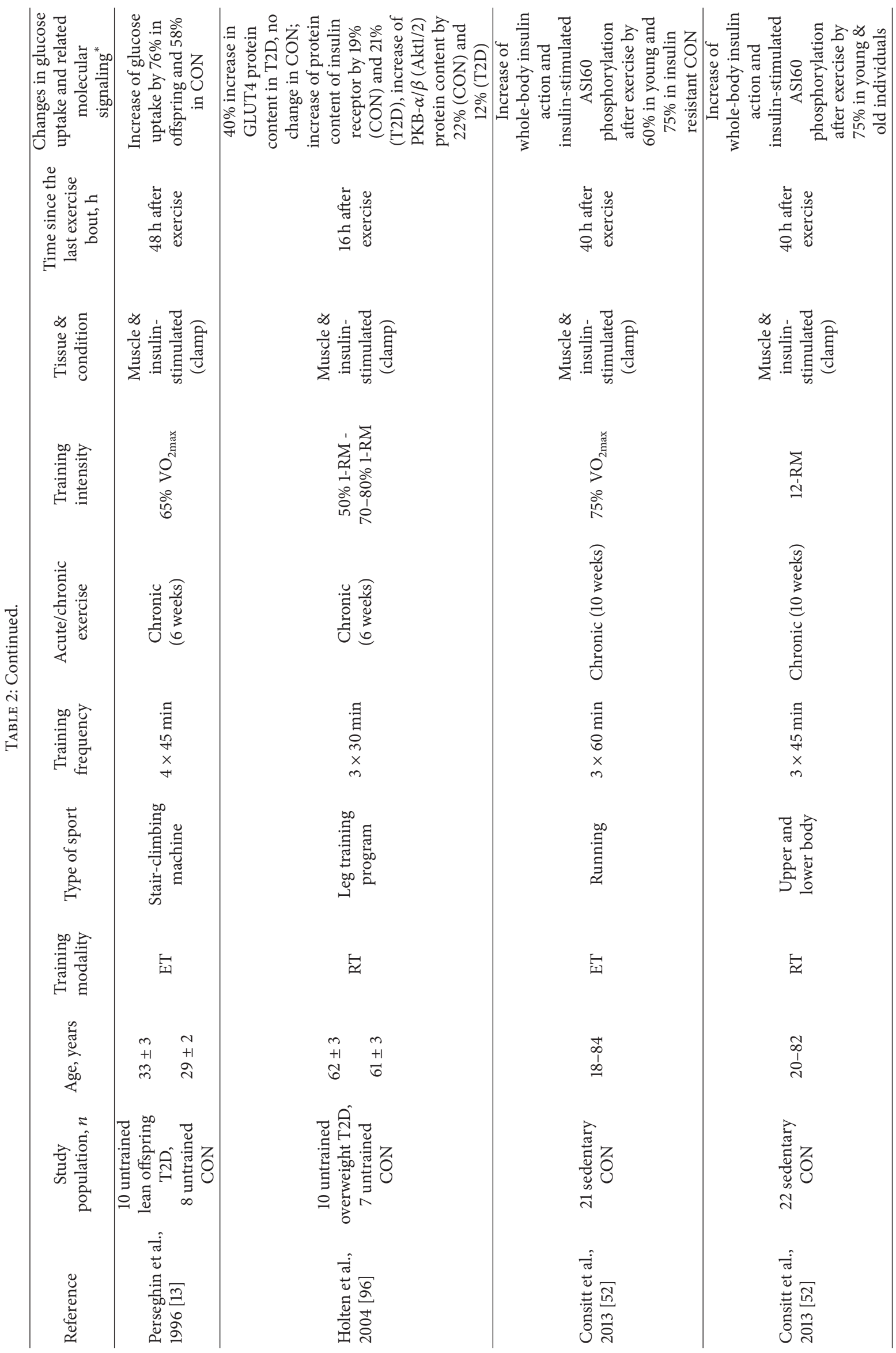




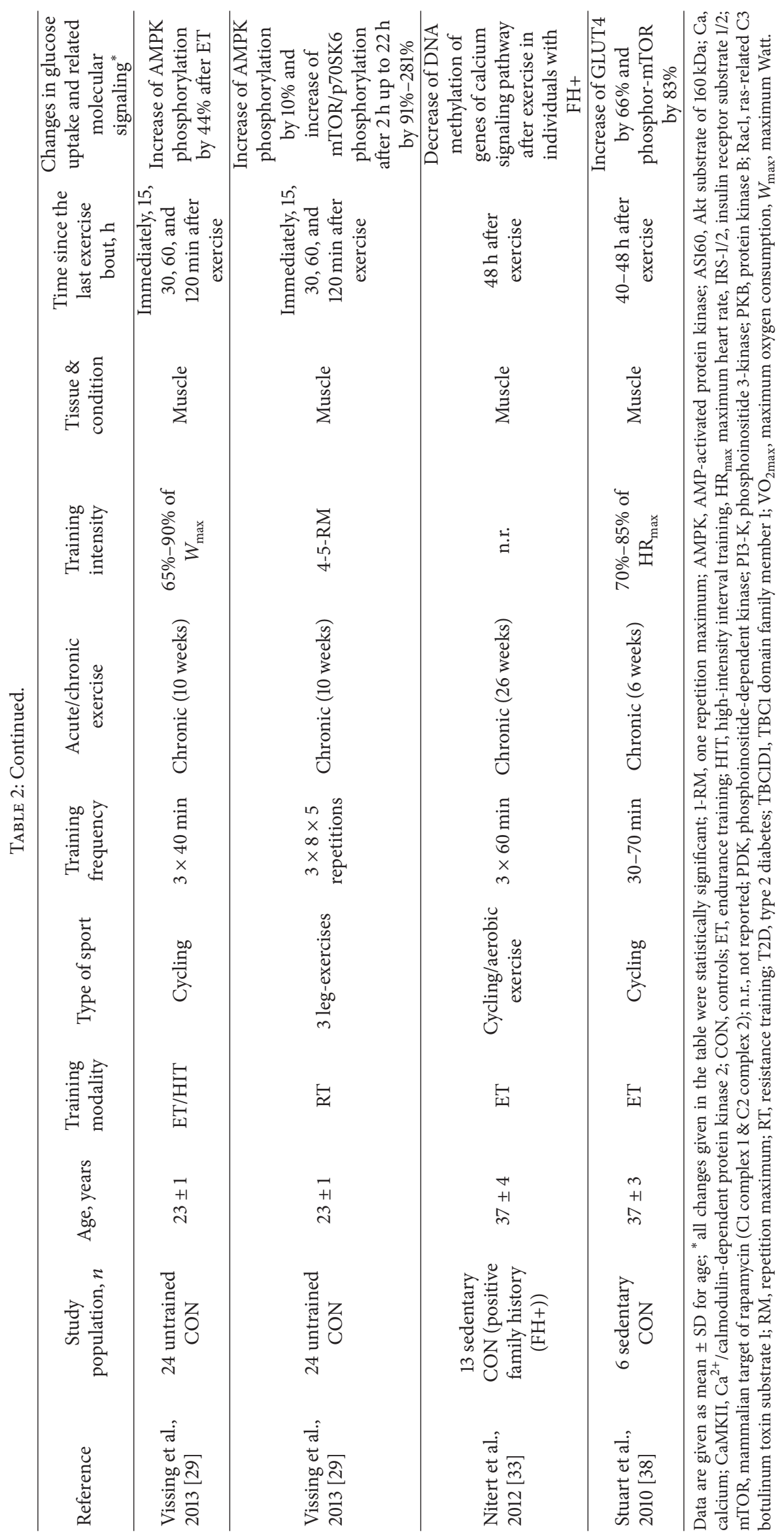




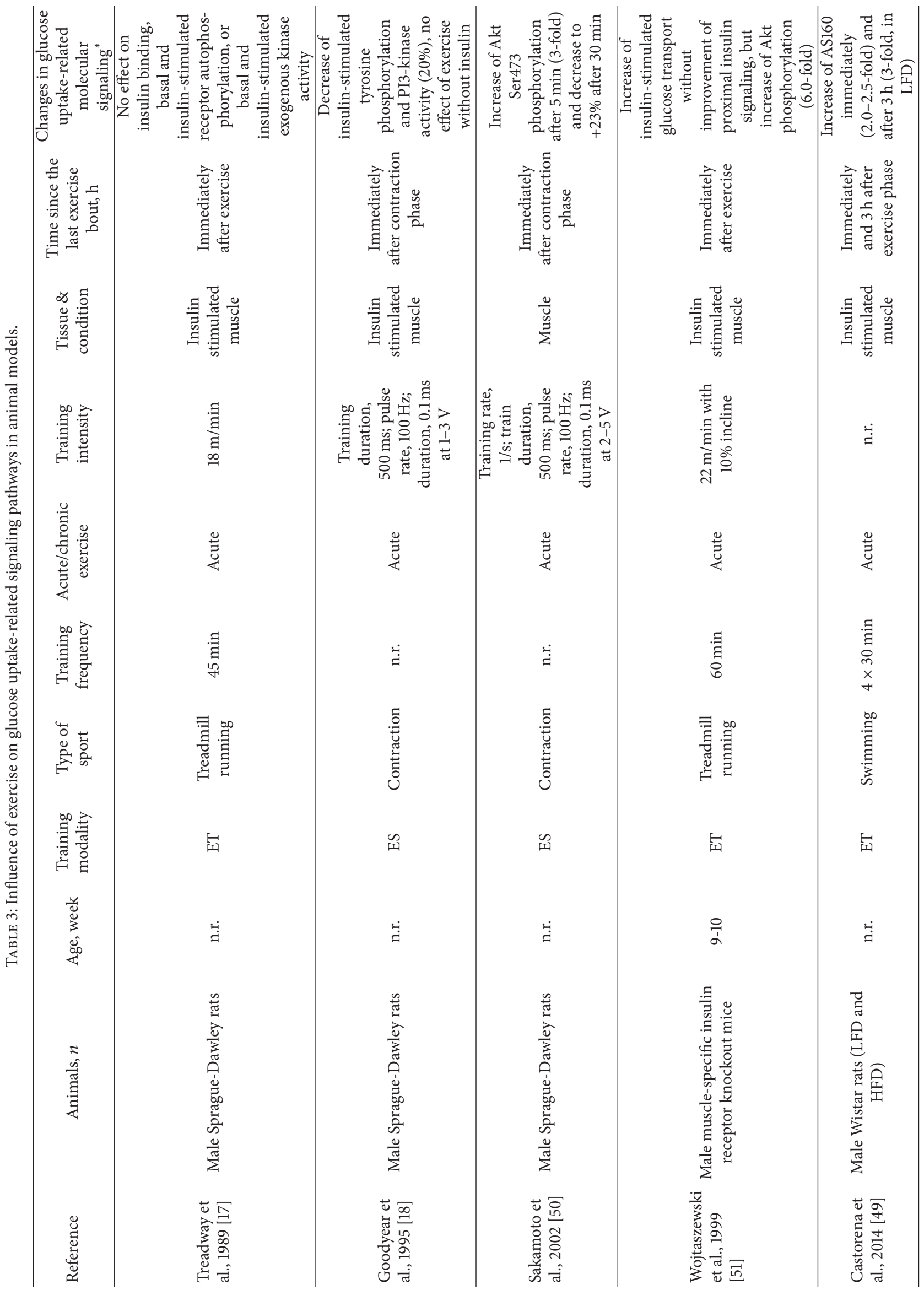




\begin{tabular}{|c|c|c|c|c|c|c|}
\hline 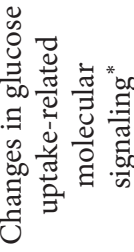 & 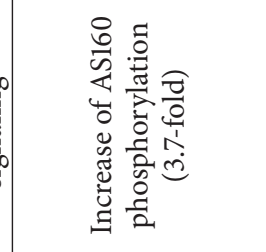 & 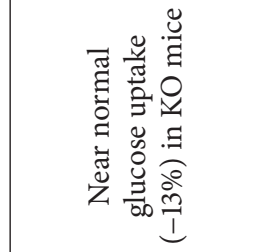 & 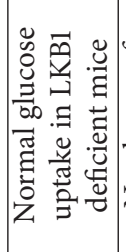 & 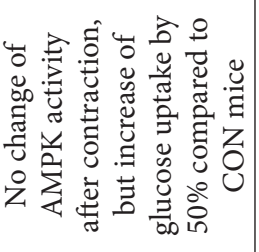 & 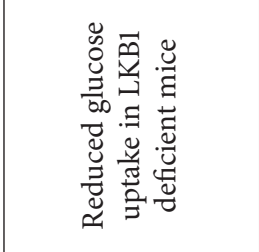 & 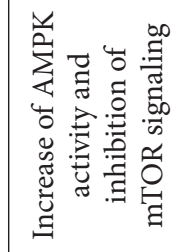 \\
\hline 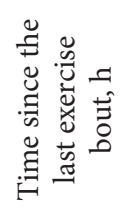 & 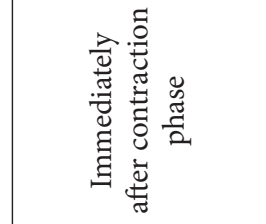 & 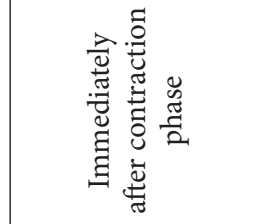 & 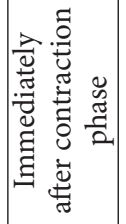 & 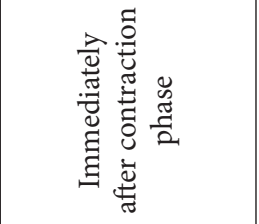 & 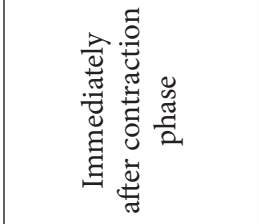 & 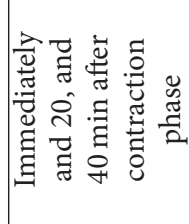 \\
\hline 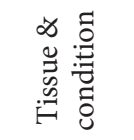 & $\begin{array}{l}\frac{\ddot{u}}{u} \\
\stackrel{0}{z}\end{array}$ & 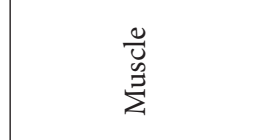 & $\begin{array}{l}\frac{\ddot{v}}{u} \\
\stackrel{g}{\Sigma}\end{array}$ & $\begin{array}{l}\frac{0}{u} \\
\stackrel{0}{\Xi} \\
\sum_{i}\end{array}$ & $\begin{array}{l}\stackrel{0}{u} \\
\stackrel{0}{2} \\
\sum^{2}\end{array}$ & $\begin{array}{l}\frac{\ddot{v}}{\tilde{u}} \\
\stackrel{\underline{z}}{\Sigma}\end{array}$ \\
\hline 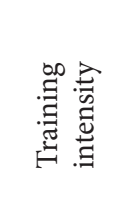 & 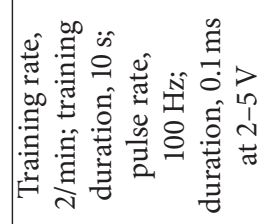 & 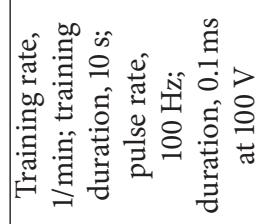 & 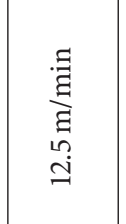 & 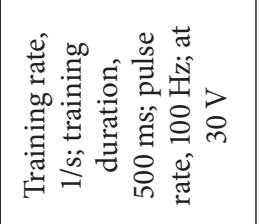 & 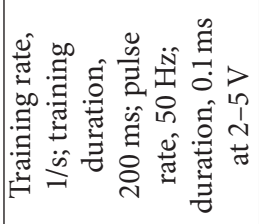 & 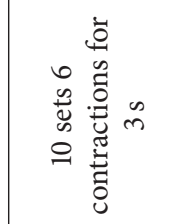 \\
\hline 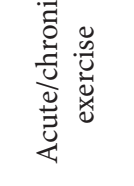 & 苞 & 蒁 & 蒁 & 蒁 & 苞 & 苛 \\
\hline 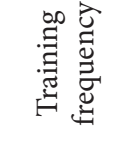 & 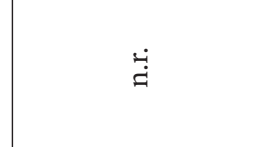 & 古 & $\begin{array}{l}\stackrel{\Xi}{\Xi} \\
\stackrel{\sim}{\sim}\end{array}$ & $\underset{\text { 塄 }}{ }$ & 百 & 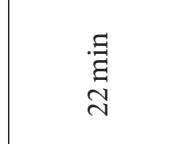 \\
\hline 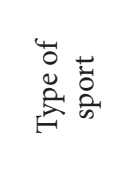 & 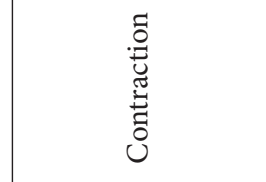 & 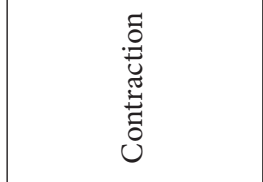 & 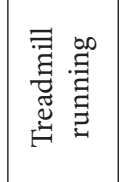 & 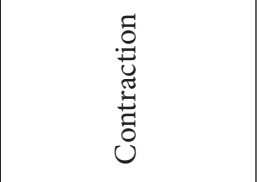 & 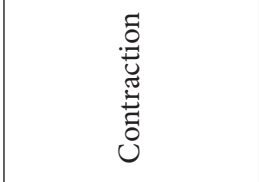 & 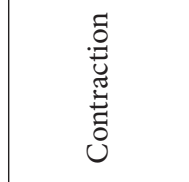 \\
\hline 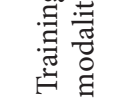 & 占 & 杄 & 空 & 峼 & 望 & 占 \\
\hline 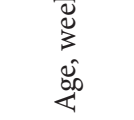 & ப் & $\begin{array}{l}0 \\
1 \\
0\end{array}$ & $\begin{array}{l}\stackrel{\widehat{N}}{b} \\
\underline{b}\end{array}$ & $\dot{\leftrightarrows}$ & $\dot{\leftrightarrows}$ & $\approx$ \\
\hline 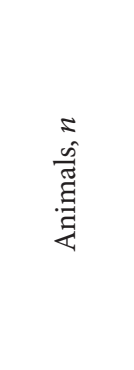 & 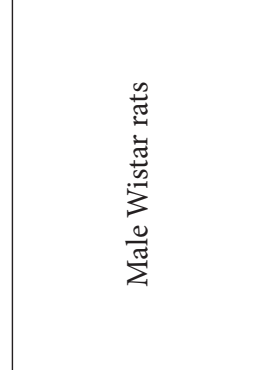 & 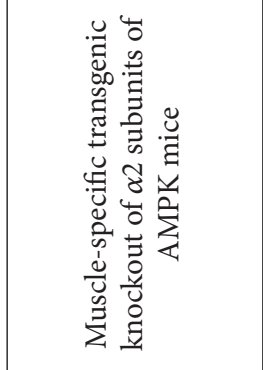 & 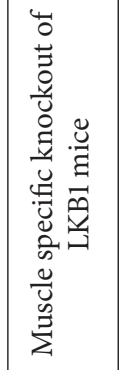 & 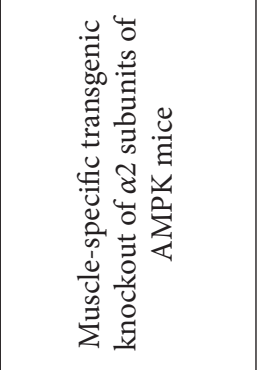 & 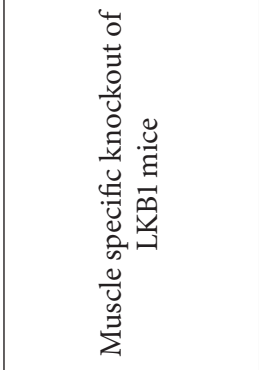 & 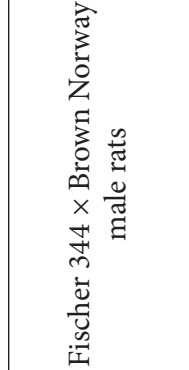 \\
\hline 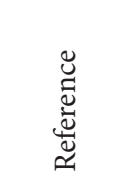 & 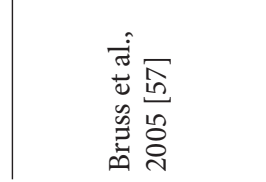 & 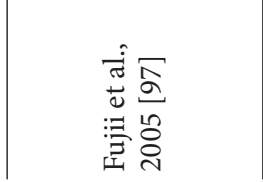 & 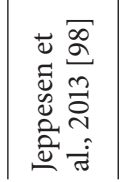 & 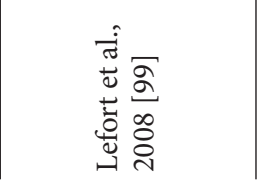 & 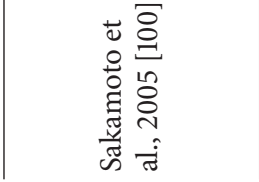 & 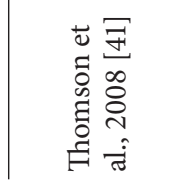 \\
\hline
\end{tabular}




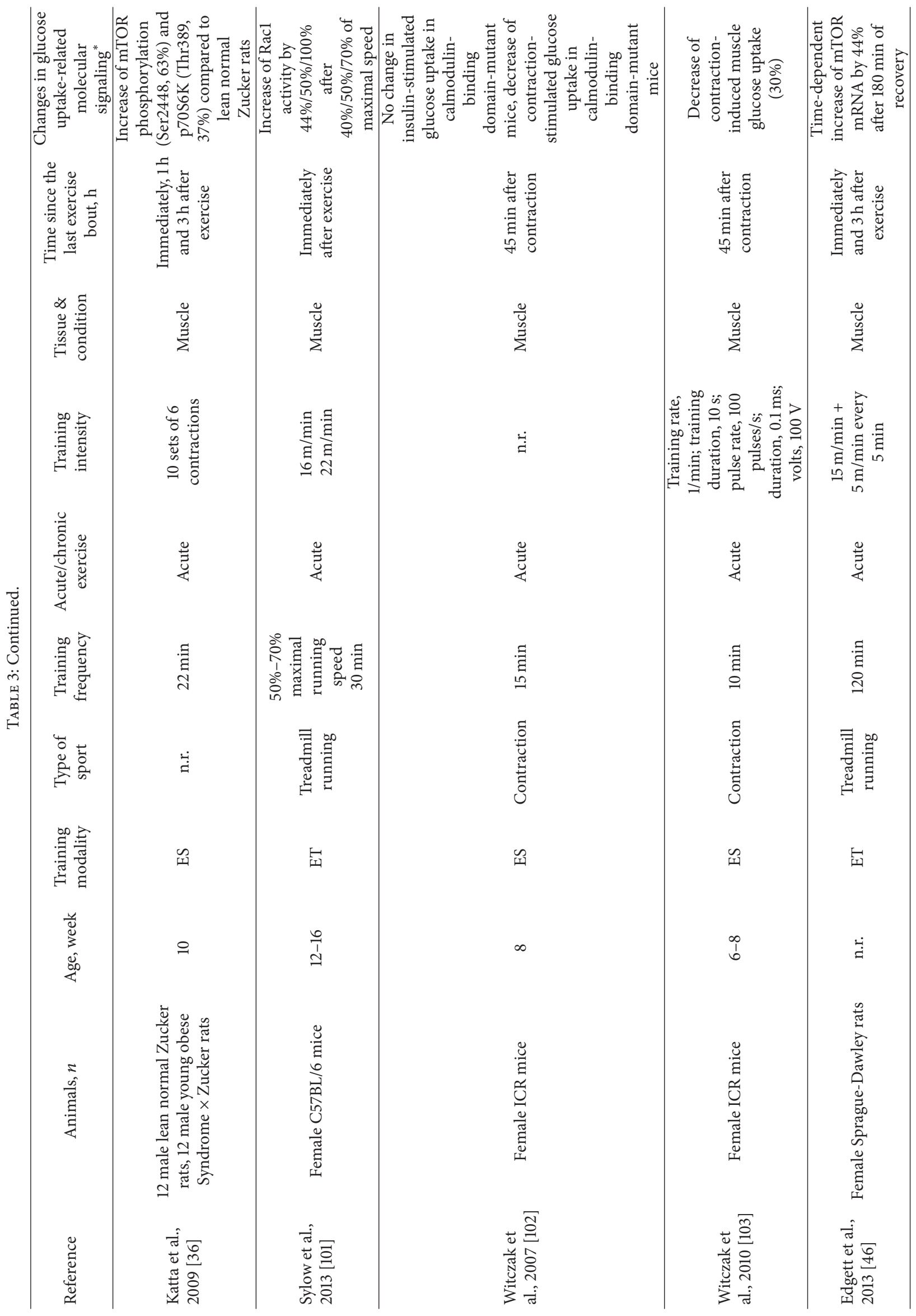




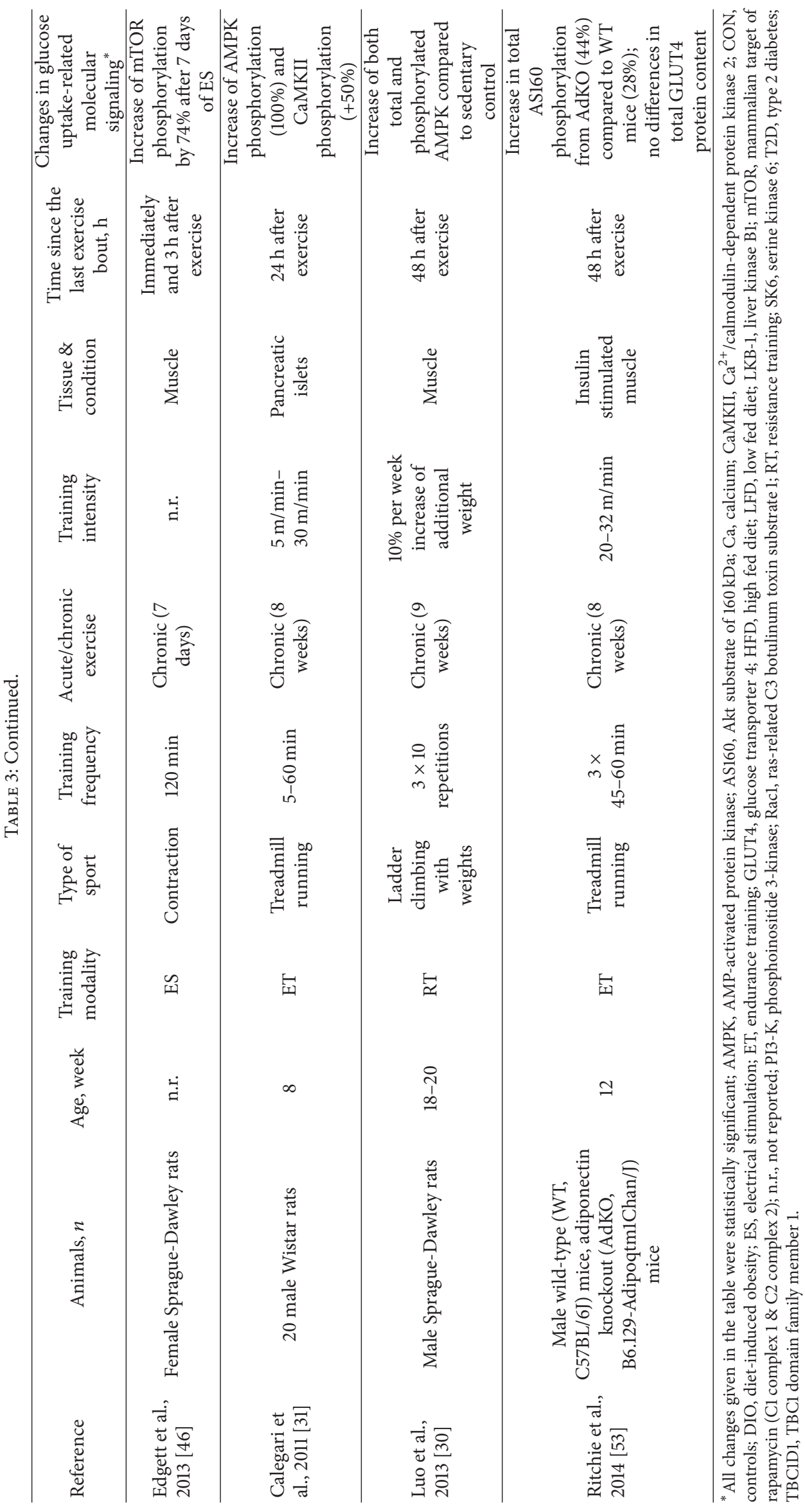




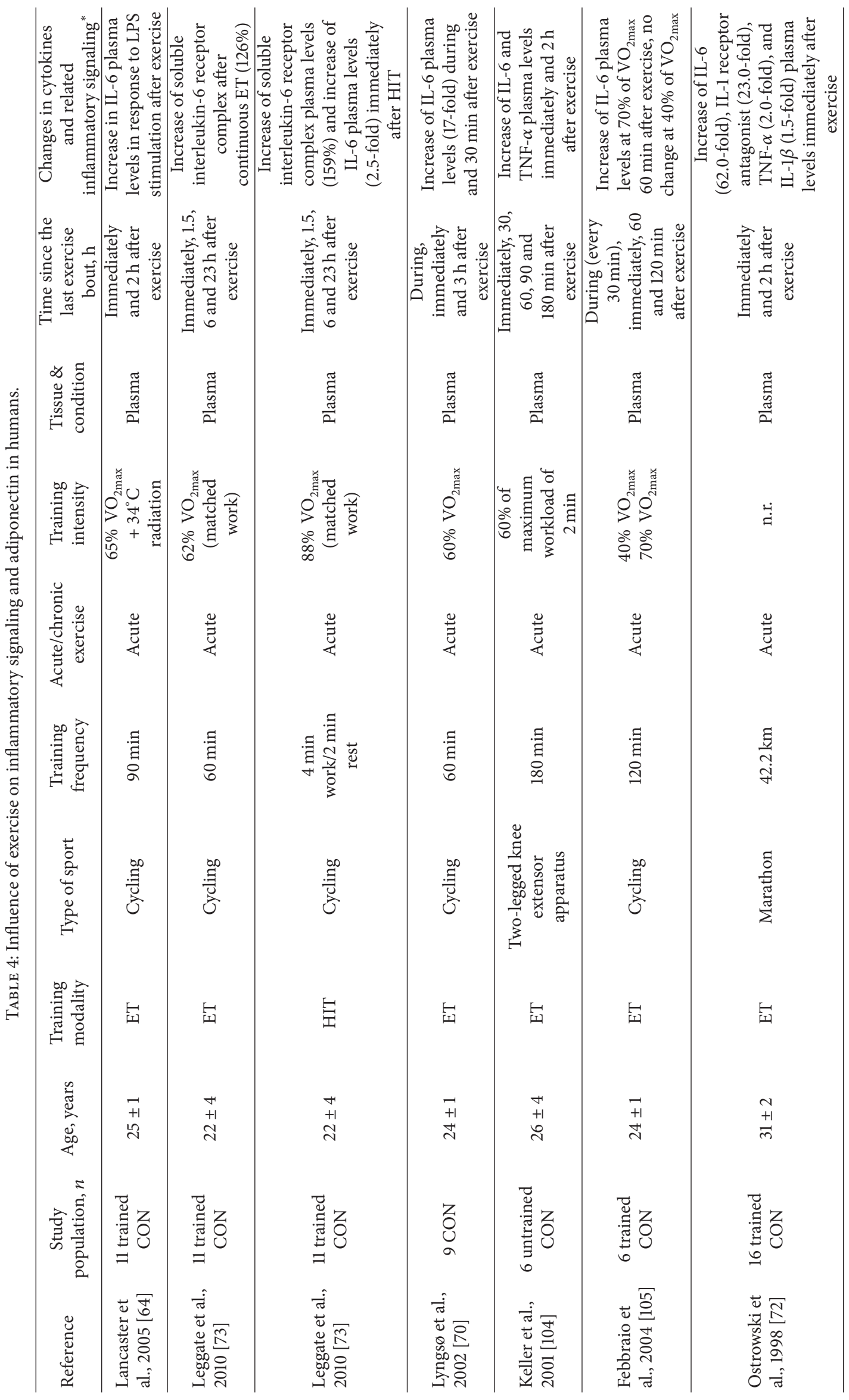




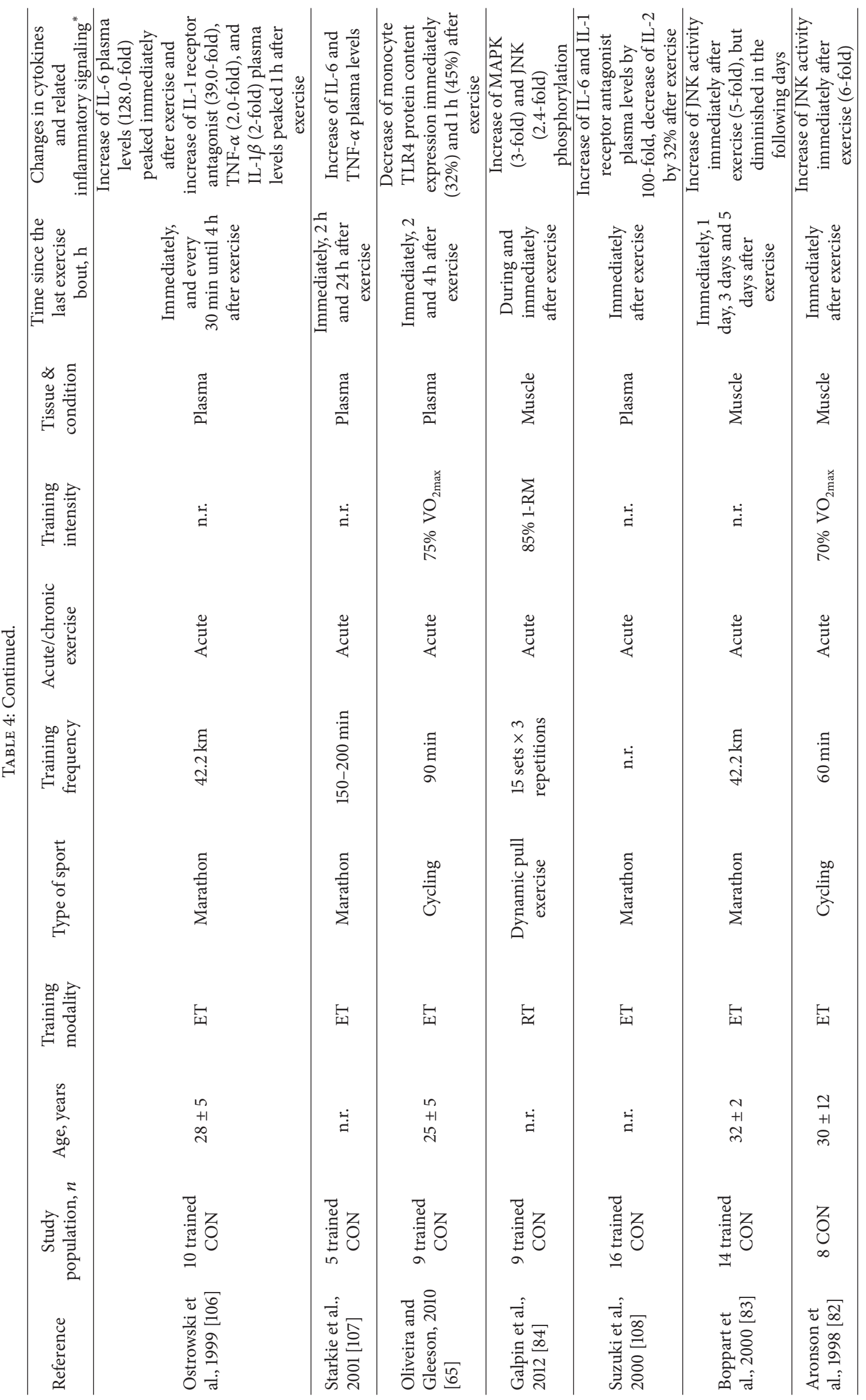




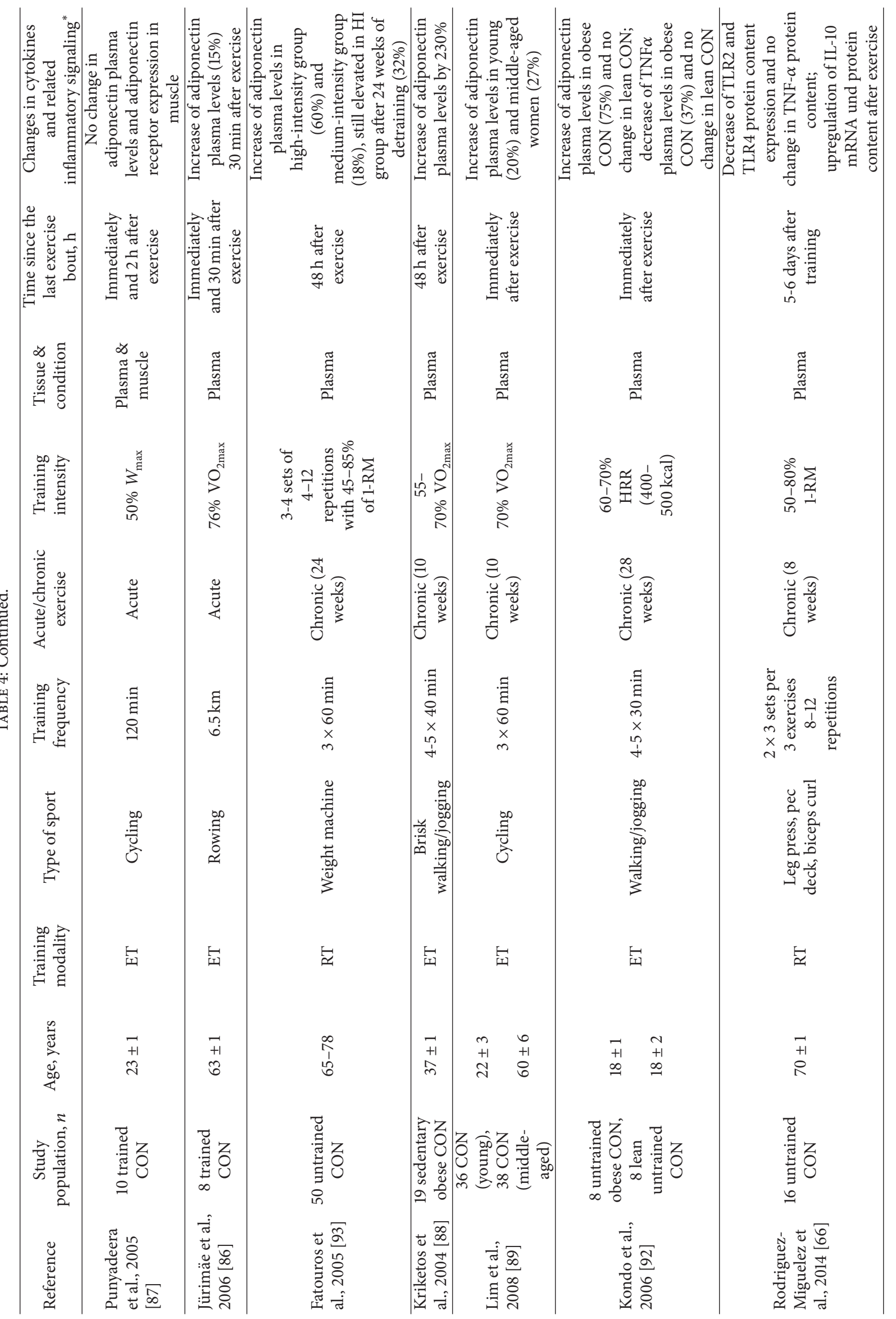




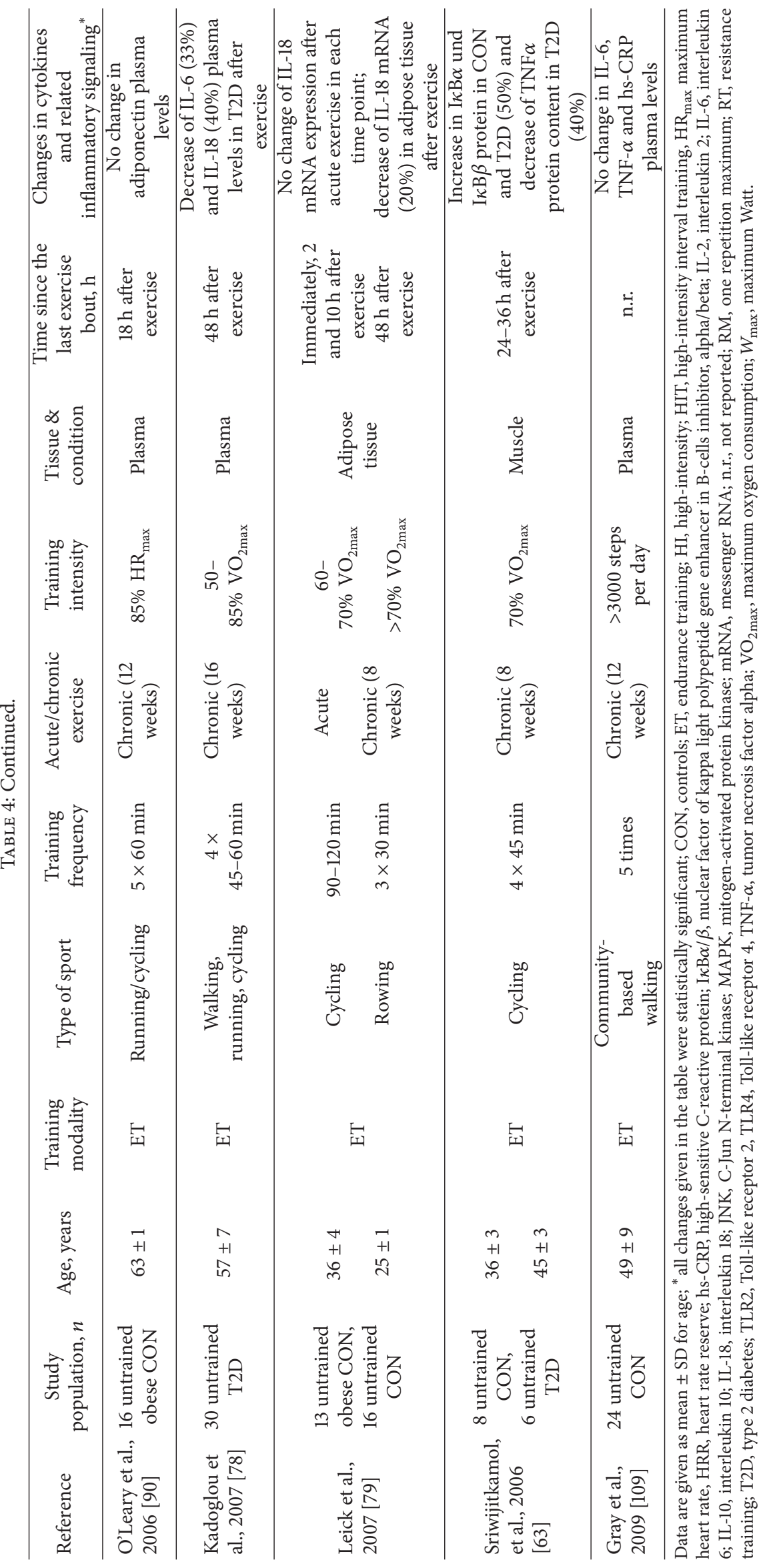




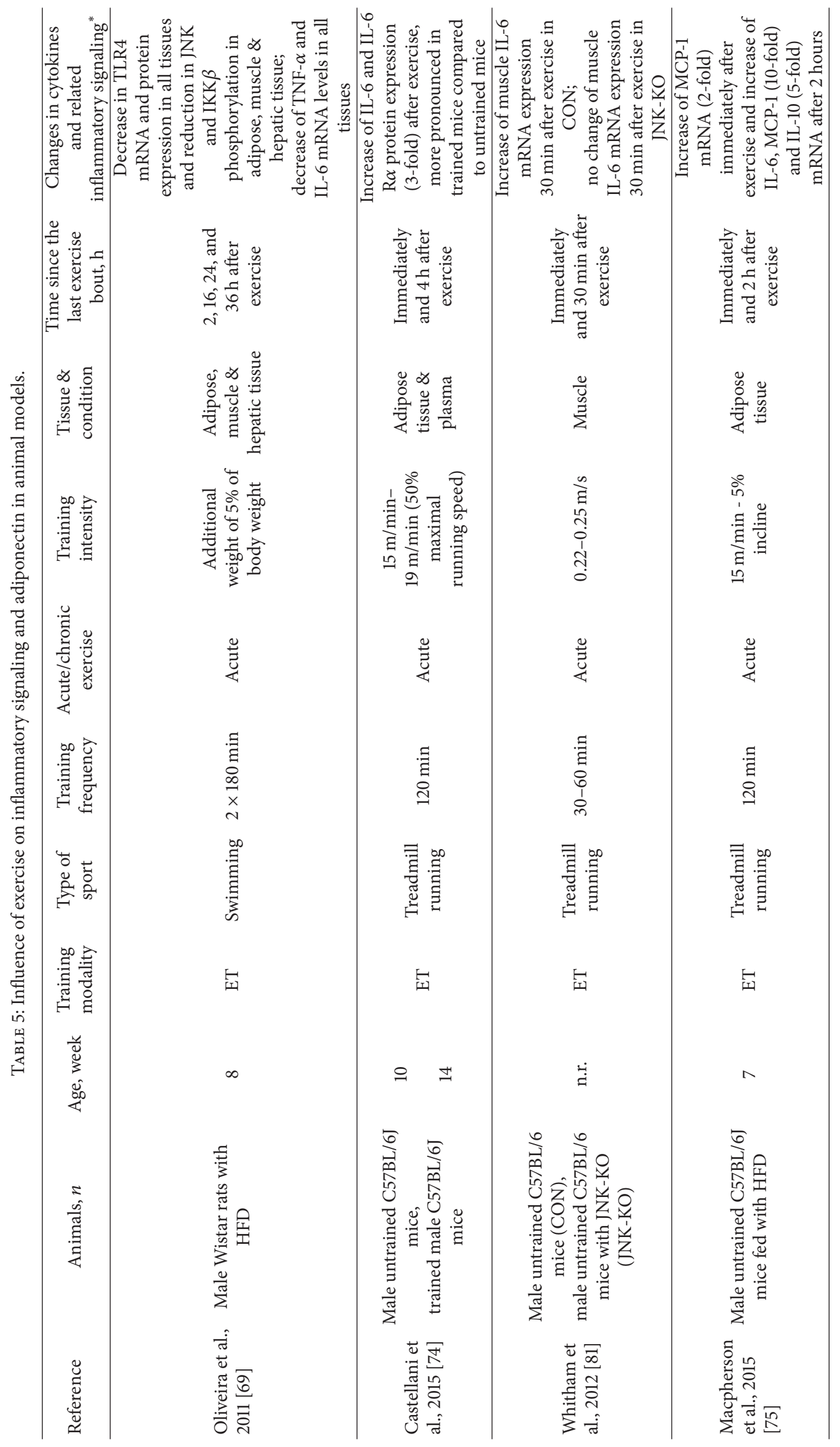




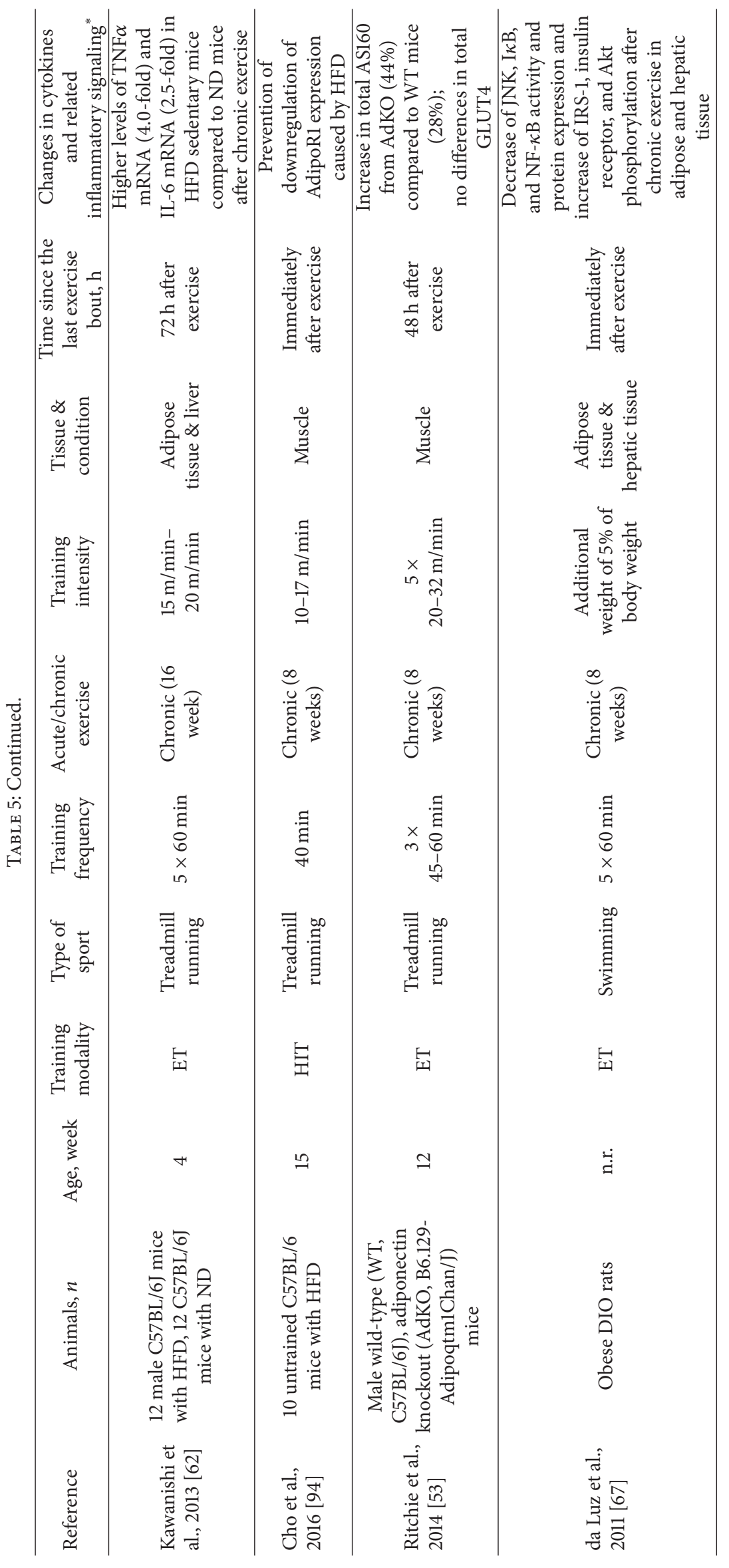




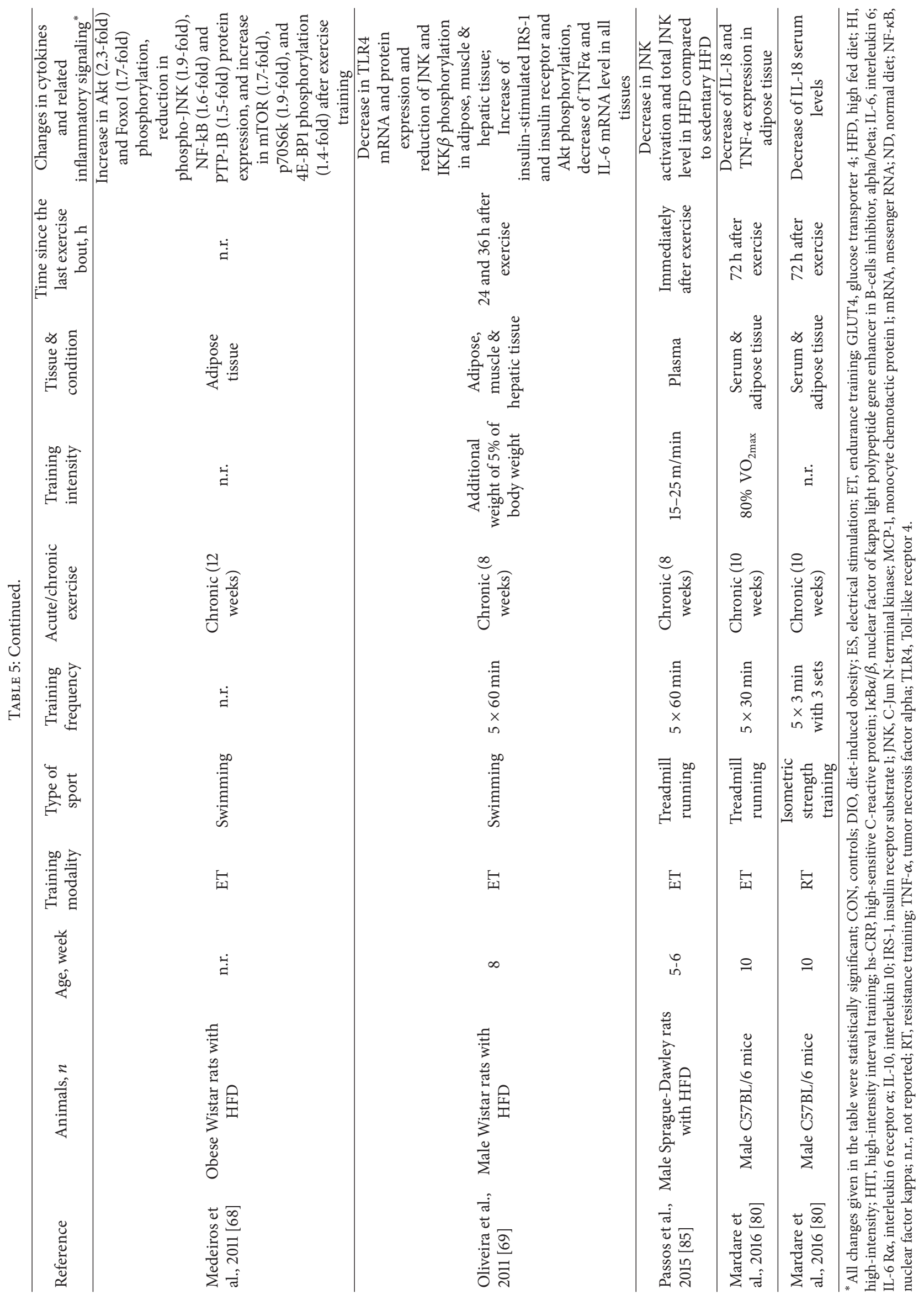




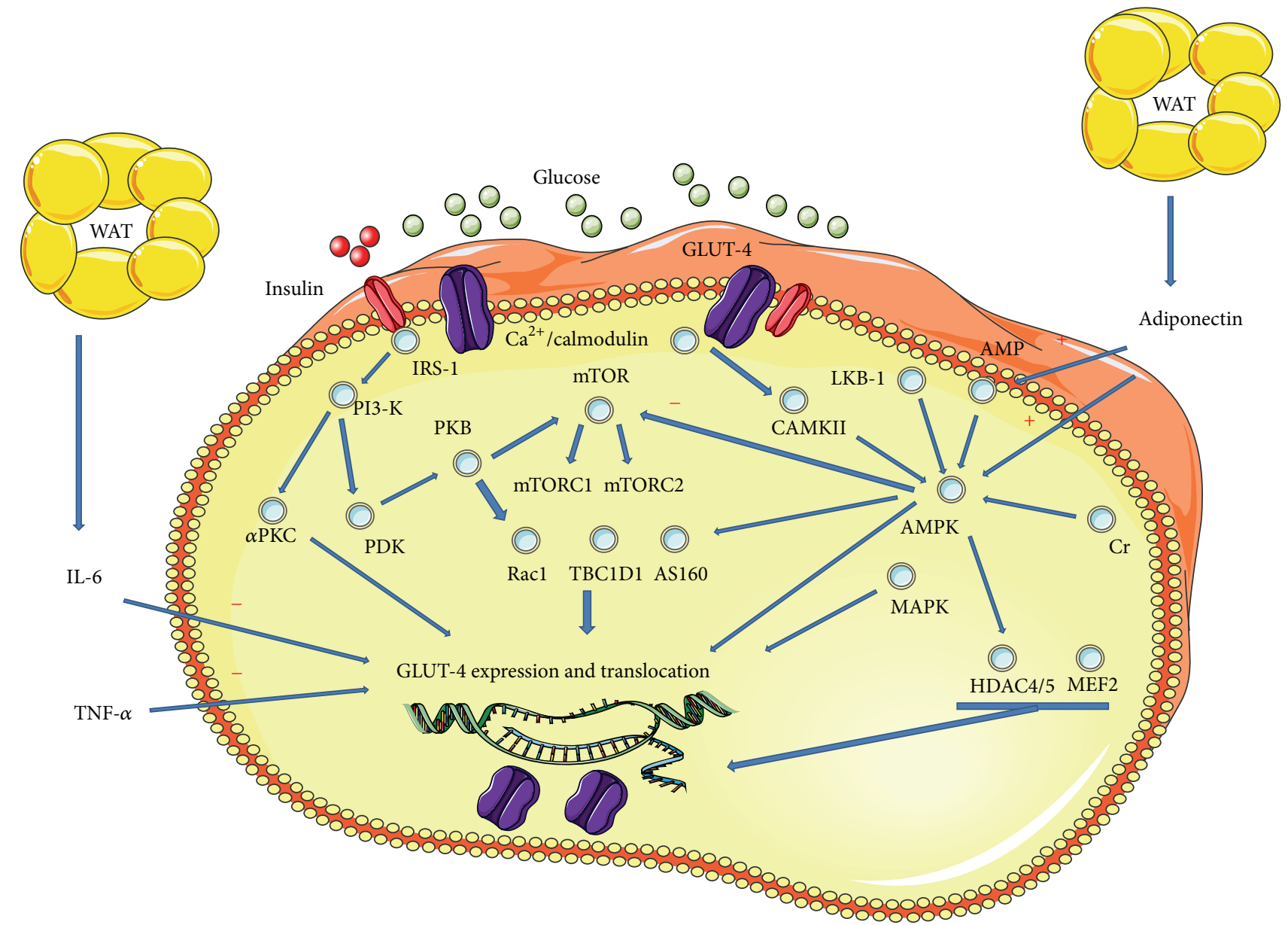

FIGURE 1: Interaction of important key players in exercise mediated glucose uptake of human muscle cells. A proposed model for the key players in glucose transport after physical exercise. $\alpha \mathrm{PKC}$, atypical PKC; AMP, adenosine monophosphate; AMPK, AMP-activated protein kinase; AS160, Akt substrate of $160 \mathrm{kDa}$; Ca, calcium; CaMKII, $\mathrm{Ca}^{2+} /$ calmodulin-dependent protein kinase 2; Cr, creatine; GLUT-4, glucose transporter 4; HDAC4/5, histone deacetylase 4/5; IL-6, interleukin 6; IRS-1, insulin receptor substrate 1; LKB-1, liver kinase B1; MEF2, myocyte enhancer factor-2; MAPK, mitogen-activated protein kinases; mTOR, mammalian target of rapamycin (C1 complex 1 and $\mathrm{C} 2$ complex 2); PDK, phosphoinositide-dependent kinase; PI3-K, phosphoinositide 3-kinase; PKB, protein kinase B; Racl, ras-related C3 botulinum toxin substrate 1; TBC1D1, TBC1 domain family member 1; TNF- $\alpha$, tumor necrosis factor alpha; WAT, white adipose tissue.

p70 ribosomal S6 kinase and 4E binding protein 1 were unchanged [28] (Table 2).

While some acute exercise studies in animals showed that AMPK-deficient mice and LKB-deficient mice had a normal contraction-induced glucose uptake, which was independent of the knockout of the catalytic alpha-isoforms of AMPK [97, 98], other studies found that pharmacological inhibition of AMPK and LKB activity blunted contractioninduced glucose disposal in animal models by electrical stimulation $[99,100]$. LKB1 knock-out in muscle provoked a reduced activity of the AMPK $\alpha 2$ isoform, and transgenic mice expressing a kinase-dead, dominant negative form of the AMPK $\alpha 2$ showed also a reduced AMPK activity and blunted glucose uptake. The authors assumed that either the maximal force production was reduced in this muscle, raising the possibility that the defect in glucose transport was due to a secondary decrease in force production and not impaired
AMPK $\alpha 2$ activity, or the kinase-dead, dominant negative form of the AMPK $\alpha 2$ had a negative influence on glucose uptake $[99,100]$.

Chronic endurance as well as resistance exercise also induces AMPK activation and leads, furthermore, to changes in gene expression favoring GLUT4 translocation. AMPK phosphorylation is more strongly increased after 10 weeks of cycling at $65 \%-90 \%$ of maximum performance $\left(W_{\max }\right)$ exercise than after 10 weeks of leg-focused resistance training with an intensity of a 4-5-repetition maximum (RM) [8, 29]. In animal studies, chronic treadmill running as well as resistance training in the form of ladder climbing with weights activated AMPK phosphorylation and up-regulated expression of AMPK in rat pancreatic islets and skeletal muscle $[30,31]$ indicating that AMPK upregulation is independent of exercise modality in different tissues (Tables 2 and $3)$. 
In light of the animal studies showing that AMPKdeficient mice have a normal contraction-induced glucose uptake $[97,98]$ other molecular pathways, comprising the $\mathrm{Ca}^{2+} /$ calmodulin signaling pathway, appear to modulate exercise-induced glucose uptake and will be described in the following subsections.

3.3. $\mathrm{Ca}^{2+} /$ Calmodulin Signaling Pathway. Changes of the calcium concentration in skeletal muscle cells lead to activation of signaling cascades that influence cellular metabolism including glucose uptake [119]. In diabetes, the calcium$\left(\mathrm{Ca}^{2+}-\right)$ dependent signaling pathway and subsequently glucose uptake are impaired [120]. Genome-wide studies for DNA methylation have shown that first-degree relatives of patients with diabetes have already altered DNA methylation of genes encoding proteins involved in calcium-dependent signaling compared to healthy individuals without positive family history. However, DNA methylation decreased after 6 months of cycling and aerobic exercise [33].

As result of skeletal muscle contraction, cytosolic $\mathrm{Ca}^{2+}$ concentration and consequently the number of $\mathrm{Ca}^{2+} /$ calmodulin complexes increase. Further important key players in the $\mathrm{Ca}^{2+} /$ calmodulin signaling pathway are the $\mathrm{Ca}^{2+} /$ calmodulin-dependent protein kinases (CaMKs). These components are critical for exerciseinduced glucose uptake [32]. Downstream components of the $\mathrm{Ca}^{2+}$ /calmodulin signaling pathway are members of the histone deacetylase (HDAC) family and proteins of the myocyte enhancer factor 2 (MEF2) family leading to an enhanced expression rate of GLUT4 [8].

$\mathrm{Ca}^{2+}$ release and phosphorylation of CaMKII after acute endurance cycling exercise depend on training intensity. A matched amount of work with different intensities of $40 \%$ and $80 \%$ of $\mathrm{VO}_{2 \max }$ led to an increase in CaMKII phosphorylation by $84 \%$ immediately after high-intensity but not lowintensity cycling endurance exercise indicating that greater force outputs result in enhanced $\mathrm{Ca}^{2+} /$ calmodulin signaling [27]. Furthermore, also the duration of endurance exercise affects the $\mathrm{Ca}^{2+} /$ calmodulin signaling pathway activity, with higher activity after longer duration. A 90-min acute cycling endurance exercise resulted in a progressive increase of CaMKII activity during exercise peaking at $90 \mathrm{~min}$ of training [34]. In line with this, a recent study comparing acute HIT cycling with traditional continuous cycling exercise showed a marked increase of CaMKII activity by HIT despite the same amount of total work after $30 \mathrm{~min}$ of $70 \% W_{\max }$ [35] (Table 2).

In accordance with the acute exercise studies, a recent animal study showed that chronic endurance training on a treadmill increased the phosphorylation of CAMKII in pancreatic islets of rats in a dose-response manner [31].

In experimental mouse studies, incubation with the $\mathrm{Ca}^{2+} /$ calmodulin inhibitor KN-93 decreased skeletal muscle glucose transport [121] and inhibited electrical contractioninduced CaMKII phosphorylation [102]. In addition to the decrease of contraction-induced glucose uptake via electrical stimulation, inhibition of CaMKII resulted in an increase of AMPK activity in a recent mice study, pointing to overlapping mechanisms between these two key signaling pathways: the $\mathrm{Ca}^{2+} /$ calmodulin signaling pathway and the AMPK-signaling pathway [103]. Another key player in the context of glucose uptake-related signaling is the protein kinase mammalian target of rapamycin (mTOR) that will be addressed in the following section.

3.4. Mammalian Target of Rapamycin/Serine Kinase 6 $\left(m T O R / p 70^{S K 6}\right)$ Pathway. MTOR is a serine/threonine protein kinase that integrates diverse environmental cues by translating them into appropriate cellular responses. Disrupting the mTOR signaling pathway causes a decrease in glucose uptake in multiple cell types such as brain, muscle, and adipose tissue [122-124] and can lead to insulin resistance [125].

High-force stimuli like resistance training lead to muscle adaptation preparing skeletal muscle for more intensive stress. This muscle adaptation which appears to be dysregulated in an insulin-resistant and diabetic state is initiated by the activation of the $\mathrm{mTOR} / \mathrm{p} 70^{\mathrm{S} 6 \mathrm{~K}}$ pathway $[36,126,127]$. This protein complex activates signaling cascades including binding proteins (elF4E), initiation factors (4E-BP1), and elongation factors (eEF2) leading to protein synthesis and subsequently to cellular hypertrophy [128]. MTOR also stimulates focal adhesion kinases (FAK) and increases FAKphosphotransferase activity in order to activate muscle protein synthesis [129]. This adaptation is related to the intensity of the muscle contraction, increasing with higher training load. Acute cycling exercise of $70 \%$ of $\mathrm{VO}_{2 \max }$ as well as legspecific strength exercises of $70 \%$ of 1-RM increased mTOR phosphorylation. In particular, resistance training leads to higher activation of mTOR signaling compared to traditional endurance exercise despite a huge difference in workload (660 versus $130 \mathrm{kcal}$ ) [29, 37-39].

Protein synthesis is regulated, in particular, by contraction-induced activation of the multiprotein complex mTORC1. This protein complex functions as a sensor or control unit which regulates the translation of proteins by assessing the cellular environment for optimal conditions and initiating translation of mRNA. Besides physical activity, potent stimulators of the mTOR/S6K pathway are insulin, insulin-like growth factor (IGF-1), cytokines like IL-6, sufficient amino acid levels in skeletal muscle, and full-energy depots [130].

During acute endurance as well as resistance exercise, mTOR signaling is inhibited via AMPK phosphorylation and signaling to suppress high-energy demanding procedures such as protein synthesis [40-42]. However, after exercise, muscle protein synthesis increases in parallel to the activation of Akt/PKB (protein kinase B), mTOR, S6K, and eEF2.

One bout of intense treadmill walking at $70 \%$ of $\mathrm{HR}_{\max }$ for $45 \mathrm{~min}$ in untrained old men as well as $70 \%$ of $\mathrm{VO}_{2 \max }$ of one leg exercise for $60 \mathrm{~min}$ in untrained healthy young men led to significant activation of the insulin signaling as well as of the mTOR/SK6 pathway [43, 44]. In line with this, recent exercise studies showed that acute cyclingbased HIT or intense leg-specific strength training [40] activates the mTOR signaling pathway in human muscle $[39,45]$. Exercise-induced activation of mTOR signaling in 
leg-specific endurance and resistance training appears to be time-dependent with a continuous increase after termination of physical activity $[40,43]$. In line with the human studies, mTOR signaling was upregulated in acute exercise studies in animals comprising treadmill running and electrical stimulation, with a time-dependent answer after exercise termination [46] (Tables 2 and 3).

Chronic exercise studies also demonstrate that long-term leg-specific resistance training with $4-5-\mathrm{RM}$ in sedentary individuals and high intensity cycling with $70-85 \%$ of $\mathrm{HR}_{\max }$ in untrained controls can activate the mTOR signaling pathway in human muscle $[29,38]$. These results underline that the activation of mTOR signaling may be independent of exercise type as well as training history. Besides mTOR, there are other important downstream targets modulating glucose uptake that will be addressed in the following section.

3.5. Ras-Related C3 Botulinum Toxin Substrate 1 (Rac1), TBC1 Domain Family Members 1 and 2 (TBC1D1/2), and Akt Substrate of $160 \mathrm{kDa}(\mathrm{AS160})$. The proteins AS160, TBC1D1/2, and Racl are involved in insulin- as well as contractioninduced glucose uptake $[131,132]$ and are, therefore, points of convergence of these two pathways. These downstream targets are altered in an insulin-resistant or diabetic state showing a reduced signaling activity [101, 133-136].

Acute endurance exercise studies in untrained and trained humans showed an increase in phosphorylation of TDC1D1/4 and AS160 in skeletal muscle in the first 4 hours after cycling and specific one-leg endurance exercise, especially under long-term training conditions with a training duration of at least $60 \mathrm{~min}$ at $65 \% \mathrm{VO}_{2 \max }[16,54-56]$. In line with these human studies, animal studies found that contraction-induced glucose uptake by electrical stimulation was also modulated by an increase in phosphorylation of AS160 and TBC1D1 proteins [57] (Tables 2 and 3).

Racl, a key downstream target in the regulation of glucose uptake, was shown to modulate exercise- and insulinstimulated GLUT4 translocation in human muscle, with an intensity-dependent response pattern, as shown in murine muscle $[58,59]$. Animals were exercised at their 50\% and $70 \%$ maximum running speed over $30 \mathrm{~min}$ on a treadmill, and the higher intensity program resulted in an larger increase of Racl activation. Given that the total amount of work differed between both measurements, the results are hard to interpret. The larger improvement may result from the higher intensity or from the greater amount of exercise. A future study comprising an alternative training protocol with identical energy expenditure but different intensities would help to clarify the role of exercise intensity in this context. Furthermore, in RAC1-deficient mice, GLUT4 translocation as well as glucose uptake decreased after acute electrical stimulated muscle contraction and insulin infusion as a sign of an inhibited signaling capacity $[59,60]$.

Glucose uptake and insulin signaling are influenced by inflammatory processes and specific cytokines [2]. The following section aims at shedding some light on the impact of inflammatory signaling on exercise-stimulated glucose uptake and insulin signaling.

\section{Inflammation-Associated Signaling Pathways and Key Players}

4.1. I B Kinase/Nuclear Factor Kappa B Pathway (IKK/NF$\kappa B)$. Different environmental influences, for example, certain pathogens, can activate molecular signaling cascades leading to an inflammatory response mediated by the IKK/NF- $\kappa \mathrm{B}$ pathway. Recognizing receptors are, in particular, Toll-like receptors (TLRs). TLR4 plays a key role in the activation of the pro-inflammatory NF- $\kappa \mathrm{B}$ pathway. TLRs interact with pathogen-associated molecules, resulting in an activation of downstream signaling proteins, for example, MyD88 [137], and subsequently an immune reaction via cytokine release, for example, of IL-6 and TNF- $\alpha$ from adipose tissue. The adapter protein MyD88 also activates other inflammation-associated signaling pathways like MAPK signaling as described below in more detail [138]. TLRs are expressed on macrophages, which can be subdivided into pro-inflammatory M1 and antiinflammatory M2 macrophages. Exercise studies have shown that physical activity modulates TLR-dependent pathways [2]. As a result, acute as well as chronic exercise can lead to reduced TLR expression [61] and phenotypic switching from M1 to M2 macrophages in adipose tissue of obese mice [62].

Cytokines like IL- 6 or agents comprising microbial components trigger signaling cascades that converge in the activation of $\mathrm{I} \kappa \mathrm{B}$ kinase (IKK) enzyme complex and subsequently in a translocation of the protein complex NF- $\kappa$ B into the nucleus. This results in transcription of target genes for inflammatory immune reaction including cytokines like IL6 , TNF- $\alpha$, and IL-15 [139]. Chronic activation of the NF- $\kappa \mathrm{B}$ pathway contributes to insulin resistance and muscle wasting. Especially in type 2 diabetes, human muscle is characterized by an increased activity of this pathway [63].

Human and animal exercise studies have shown that acute as well as chronic exercise can reduce the activation of the IKK/NF- $\kappa \mathrm{B}$ pathway. This attenuation of the inflammatory signaling was independent of the exercise modality, age, and training status [63-69] (Tables 4 and 5).

During acute physical activity with a sufficient load, muscle contraction induces a marked increase of IL-6 expression in skeletal muscle but also suppresses IL-6 production in adipose tissue [70]. Increasing energy demands due to prolonged or intense acute training like marathon running or cycling at $88 \%$ of $\mathrm{VO}_{2 \max }$ [71-73] as well as shrinking depots of muscle glycogen [104] accelerate the increase of IL6 plasma levels. Interestingly, a recent work from Castellani et al. showed that exercise induces also a specific increase of IL-6 in adipose tissue which occurred more rapidly in adipose tissue from trained mice in comparison to untrained mice when exercised at the same relative running speed on a treadmill. The authors speculated that the increase of IL6 would be needed for the provision of lipids to the muscle and liver [74]. In line with this, Macpherson et al. showed an increasing IL-6 and decreasing M1 macrophages content in inguinal adipose tissue and an improved insulin action after an acute bout of treadmill running exercise in obese mice [75]. In line with the results of the acute exercises studies, chronic exercise also led to decreased activity of 
the IKK/NF- $\kappa \mathrm{B}$ pathway after 8 weeks of cycling exercise at $70 \%$ of $\mathrm{VO}_{2 \max }$ and intense whole-body strength exercise with $50-80 \%$ of 1-RM $[63,66]$ (Tables 4 and 5). Accordingly, a decreased plasma IL-6 concentration at rest as well as in response to chronic exercise appears to characterize a normal training adaptation [71].

The transient rise in IL- 6 also appears to be responsible for the production of anti-inflammatory mediators like IL10 or IL-1 receptor antagonist (IL-1RA). In particular IL1RA prevents inflammatory processes by blocking signal transduction of the proinflammatory IL-1 and creates also an anti-inflammatory balance to the proinflammatory cytokine IL-1 $\beta[76,77,140]$. Furthermore, elevated levels of IL- 6 from skeletal muscle stimulate an anti-inflammatory signaling cascade that inhibits the secretion of proinflammatory cytokines like TNF- $\alpha$ or IL- $1 \beta$, suppress the secretion of the acutephase reactant C-reactive protein (CRP) from the liver, a general and unspecific marker for systemic inflammation [76, 77], downregulate monocyte TLR expression at both mRNA and cell surface protein levels, and finally inhibit the IKK/NF- $\kappa$ B pathway [64-66]. Besides the TLR family, there are other receptor proteins like NOD-like receptors initiating inflammatory processes and subsequently modulating glucose uptake-related signaling which will be discussed in the following section.

4.2. Inflammasome Pathway. The NOD-like receptor (NLR) family is of key importance in the innate immune system. NLRs are responsible for recognizing pathogen and dangerassociated molecular patterns. In response to stress signals, NLRs activate the inflammasome pathway which forms a multi-protein complex [2]. Participating components of inflammasome complexes are NLRs, neutrophilic alkaline phosphatases (NALPs), apoptosis-associated speck-like protein (ASC) and caspase-1. After its formation, this oligomer converts proinflammatory cytokines into active forms such as IL-1 $\beta$. Increasing IL-1- $\beta$ levels have been hypothesized to play a role in the progression of type 2 diabetes and its complications because its activity stimulates inflammatory processes leading to cell damage and apoptosis, in particular in pancreatic $\beta$-cells. Furthermore, IL-1 $\beta$ inhibits proximal and distal insulin signaling and mediates interorgan cross talk between adipocytes and the liver, contributing to systemic inflammation [2, 141-143].

A recent review reported that chronic endurance and resistance training in mice decrease NLR family pyrin domain containing 3 (NLRP3) mRNA levels accompanied by reduced IL-18 levels, reflecting diminished activity of the NLR/inflammasome pathway [2]. IL-18 expression decreases under chronic intense endurance exercise conditions with sports like rowing, running, or cycling with an intensity which is at $70 \%$ of $\mathrm{VO}_{2 \max }$ in humans $[78,79]$. Only chronic training conditions, but not acute exercise, appear to reduce IL-18 mRNA expression [79]. In line with this, a recently published animal study with chronic treadmill running as endurance exercise and isometric strength training as resistance training showed a decrease of IL-18 expression in adipose tissue and plasma levels [80] (Table 5).
So far, there are no human exercise studies which measured acute or chronic effects of physical activity on the upstream elements of the inflammasome pathway. Further mechanistic studies are, therefore, needed to better understand the role of the inflammasome in the antiinflammatory response to exercise. In contrast, the role of the C-Jun N-terminal kinase (JNK)/mitogen-activated protein kinase (MAPK) pathway in the modulation of exercisedependent effects on glucose uptake and inflammatory response has been investigated by several animal as well as human studies.

\subsection{C-Jun N-Terminal Kinase (JNK)/Mitogen-Activated} Protein Kinase (MAPK) Pathway. Lipid accumulation in adipocytes and endoplasmic reticulum (ER) stress as well as a NF- $\kappa$ B dependent cytokine releases activate the JNK/MAPK pathway $[139,144]$. This activation results in the serine phosphorylation of IRS-1 and the phosphorylation of the c-Jun component of activator protein-1 (AP-1). The phosphorylation of serine residues in insulin receptor substrate1 leads to an impairment in the ability of IRS- 1 to activate downstream phosphatidylinositol 3-kinase-dependent pathways which may cause insulin resistance [145-147]. AP-1 is a transcription factor that mediates the gene expression of many cytokines. Subsequently, the JNK pathway leads to an inflammatory reaction, especially to TNF- $\alpha$ and IL- 6 release [139]. JNKs are divided into 3 isoforms and belong to the MAPK family. The MAPK family comprises extracellular regulated kinases (ERKs), JNKs and p38, and mediates cell growth, differentiation, hypertrophy, apoptosis, and inflammation [144]. Furthermore, oxidative stress following reactive oxygen species (ROS) production induces JNKs and p38 MAPK activation reflecting an important immune defense mechanism [148]. JNK activation by skeletal muscle contraction is also associated with an increase in muscle IL-6 mRNA expression in mice acutely after endurance exercise in form of treadmill running [81].

Exercise studies in human and animal models showed that the JNK/MAPK pathway is activated in a doseresponse pattern. In particular very intense acute exercise like marathon running or cycling at $70 \%$ of $\mathrm{VO}_{2 \max }$ and intense dynamic pull exercise as resistance training with an onerepetition maximum (1-RM) of $85 \%$ stimulate JNK signaling in skeletal muscle [82-84], independently of training modality. JNK activation results, as a physiological mechanism, in DNA repair and muscle regeneration [149]. In contrast, a recent animal study has shown that acute long-term exercise by swimming for 180 min reduces JNK phosphorylation and improves insulin signaling and sensitivity in adipose tissue from obese rat [69]. In particular, chronic endurance exercise in form of swimming and treadmill running contributes to a reduction in JNK phosphorylation and improves insulin signaling and sensitivity in adipose and hepatic tissue from obese rats $[67-69,85]$.

Inflammatory signaling pathways are associated with insulin resistance and impaired glucose uptake, whereas adiponectin is an important, though controversially discussed, counterpart being positively associated with insulin 
sensitivity. This adipokine will be discussed in the following section.

4.4. Adiponectin. Adiponectin, an adipokine which is primarily released by white adipose tissue (WAT), appears to be a key player in glucose metabolism at least in rodents, whereas its relevance in humans is somewhat less clear [6]. The secreted adiponectin binds to its receptors AdipoR1 and AdipoR2 and activates AMPK, p38 MAPK, and peroxisome proliferator-activated receptor $\alpha$ (PPAR- $\alpha$ ) following adaptor protein 1 (APPL1) release in skeletal muscle and liver [150]. As a result, adiponectin positively affects metabolism by increasing fatty acid oxidation and glucose uptake in muscle. Furthermore, it plays a critical role in the cross talk between different insulin-sensitive tissues [151, 152]. Adiponectin levels are decreased in patients with diabetes and low adiponectin levels are associated with insulin resistance and obesity $[153,154]$. Recent mouse studies showed that pharmacological adiponectin agonists improve insulin sensitivity and other health-related parameters [155].

Only a limited number of acute exercise intervention studies focused on changes of adiponectin levels. In one study, circulating adiponectin levels increased $30 \mathrm{~min}$ after endurance exercise in the recovery phase [5]. The currently available data indicate that adiponectin levels change in dependence of exercise intensity, showing an increasing level by enhanced training intensity of $76 \% \mathrm{VO}_{2 \max }$ in trained rowing athletes [86], whereas moderate and long-lasting cycling at $50 \%$ of $\mathrm{VO}_{2 \max }$ for $120 \mathrm{~min}$ did not acutely increase adiponectin levels in trained individuals immediately after exercise [87] (Table 4).

Conflicting results were also observed under chronic exercise conditions. More intense endurance exercise in form of cycling and brisk walking at $70 \%$ of $\mathrm{VO}_{2 \max }$ resulted in increases of adiponectin levels [88, 89]. Overweight and age seem to reduce the response of adiponectin to exercise [90]. In line with this, Simpson and Singh reported in their review that adiponectin expression levels are increased under high-intensity exercise conditions [91], regardless of training modality in untrained young lean or obese individuals, after chronic whole-body strength training or jogging $[92,93]$. In line with this, Cho et al. showed that 40 minutes of HIT exercise on treadmill prevent the downregulation of AdipoR1 which was caused by a high fat diet in sedentary control animals [94] indicating the importance of intense training for the potential role of adiponectin.

In contrast, untrained and trained adiponectin knockout mice (AdKO) significantly increased glucose tolerance and insulin sensitivity after 8 weeks of treadmill running suggesting the presence of an unknown compensatory mechanism [53].

A recent meta-analysis found that chronic exercise did not significantly increase adiponectin levels. However, in subgroup analyses, all modalities tended to increase adiponectin. The lack of statistical power due to small group sizes may have contributed to the overall null-finding [3]. In contrast, lifestyle interventions with unstructured exercise alone or in combination with weight-reducing diet can positively influence adiponectin plasma levels [156]. Weight loss is an important factor contributing to increases in plasma levels of adiponectin [157-159]. In conclusion, the impact of exercise on adiponectin levels needs further clarification. With respect to chronic effects it is important to investigate to what extent exercise effects on adiponectin may be mediated by weight loss.

4.5. Exercise, Inflammation, and Insulin Signaling. Circulating serum or plasma levels of cytokines are strongly linked with the onset of type 2 diabetes [160-162]. The stimulation of inflammatory signaling cascades can lead to interference with the insulin signaling pathway [2]. During exercise, acute effects on cytokine regulation comprise an upregulation of both (i) proinflammatory cytokines (e.g., TNF- $\alpha$, IL-1 $\beta$, and IL-6) and (ii) anti-inflammatory cytokines (IL-1RA, IL-10) [106].

Long-term effects of physical exercise are known to reduce markers of inflammation by decreasing adipocytokine production and cytokine release from skeletal muscle [163-165]. The relationship between glucose uptake and adiponectin, IL-6, and TNF- $\alpha$ is shown in Figure 1.

The mechanistic impact of inflammation on insulin signaling has been studied for several cytokines. Currently available data suggest that TNF- $\alpha$ plays a direct role in the development of insulin resistance by decreasing glucose uptake into adipocytes via suppression of insulin receptor activity, AMPK activation, and downregulation of GLUT4 expression [165-168]. Acute exercise did not change the expression pattern of TNF- $\alpha$ [169], whereas the increase of TNF- $\alpha$ during high intense physical activity like marathon running appears to be a response to muscle damage [104, $107,108,170]$. Large cohort studies show that physical activity or chronic endurance exercise in form of walking reduces systemic subclinical inflammation [92] and the impact of exercise rises in a dose-response pattern regulated by frequency and intensity, but inflammation remains unchanged when exercise intensity was only moderate $[66,109,171,172]$. A moderate community-based walking program with 3000 steps more per day did not change TNF- $\alpha$ plasma levels [109] and a chronic resistance training with only 2 units per week of only 3 sets of 3 exercises had also no impact on TNF- $\alpha$ protein content. In line with this, TNF- $\alpha$ plasma levels were reduced by high-intensity chronic resistance training, even though fat mass has not changed [173]. Also animal studies show that chronic exercise training, in particular endurance training like treadmill running, can reduce TNF- $\alpha$ levels [62].

IL-6 is another important protein in this context and is expressed by several tissues. As a myokine, muscle-derived IL-6 is acutely upregulated during exercise exposure [106] and mediates a physiological cross talk with WAT and liver in order to regulate glucose metabolism [160]. However, long-term effects of regular exercise show marked decreases of IL-6 levels [77]. The role of IL-6 is complex, as also evident by its diverse effects on molecular signaling. In adipose tissue, IL-6 mediates inflammatory processes and causes insulin resistance by downregulating GLUT4 and IRS1 expression [139]. Furthermore, increasing IL-6 levels block 
PI3-K, another key player in insulin signaling, and induce TLR4 gene expression leading to enhanced inflammatory processes [174, 175]. In addition, IL-6 induces the downstream NF- $\kappa$ B signaling pathway which impairs insulin signaling and subsequently induces insulin resistance in insulin-dependent tissues of obese humans and animals [2]. In particular, IL-6 and liver interact in the context of exercise. A human exercise study with long-term cycling has shown that contractioninduced IL-6 release increased endogenous glucose production (EGP), thus underlining the importance of IL-6 for glucose homeostasis [105].

Experimental studies using mouse models yielded controversial findings. IL-6-deficient mice can develop a glucoseintolerant and insulin-resistant state indicating that balanced IL-6 levels have a positive effect on glucose uptake. Furthermore, mouse studies showed that circulating IL-6 levels increase glucose uptake and improve insulin sensitivity in skeletal muscle via AMPK activation [176].

Besides, the inflammasome pathway downregulates insulin signaling. The inflammasome pathway which is part of the innate immune system converts proinflammatory cytokines into active forms such as IL-1 $\beta$ or IL-18 which are decreased in their levels after chronic exercise [2]. Important proinflammatory chemokines which are influenced by exercise are interleukin 8 (IL-8) and monocyte chemoattractant protein-1 (MCP-1). Both cytokines slightly increase after acute exercise; however, their circulating levels decrease after chronic exercise in human as well as animal model exhibiting an improved inflammation status $[75,77,139,160]$, as shown in Table 1 .

\section{Summary}

Exercise is an important cornerstone in the prevention and treatment of metabolic disorders. Acute and chronic exercise activates different molecular signaling pathways that can counteract defects in signaling and associated metabolic processes (Table 1). Exercise interventions have shown that physical activity can increase GLUT4 protein expression and translation by activation of different molecular signaling pathways irrespective of the exercise modality. AMPK and $\mathrm{Ca}^{2+} /$ calmodulin signaling pathways show a dose-response pattern and increase their activity with increasing intensity despite equal work rate in kcal when compared to less intense exercise.

The key players mTOR, AS160, TBC1D1/4, and Racl can be activated by exercise. Human exercise studies have demonstrated that acute and chronic physical activity, regardless of training modality, leads to increases in their activity and finally to improved glucose uptake. The change in activity reflects a dose-response pattern. MTOR and AS160 also exhibit a continuous time-dependent increase.

Metabolic disorders are accompanied by activated inflammation-related signaling pathways which result in elevated cytokine release. Proinflammatory immune mediators, like IL-1 $\beta$, IL- 6 , or TNF- $\alpha$, are important factors in the development of insulin resistance. Their expression is modulated by physical activity. In particular, chronic endurance and resistance training and high training intensity improve glucose uptake which is associated in the long term with decreased secretion of proinflammatory cytokines and increased release of anti-inflammatory proteins such as adiponectin.

In summary, the current literature points to a higher efficiency of more intense exercise because of a dose-response relationship regulating metabolic improvements. However, more high-quality exercise interventions as well as mechanistic studies have to be performed to fully understand the molecular mechanisms contributing to metabolic improvements.

\section{Open Questions}

Despite the high number of studies on exercise interventions and underlying mechanisms that have been conducted, we are far from understanding the details mediating the effects of exercise on glucose uptake. Single key players in this field were identified over time and confirmed with mechanistic human and animalstudies. So far, there is still a lack of knowledge about the underlying mechanisms of exercise-induced glucose uptake in regard to training factors, such as point of termination or intensity, especially in proximal insulin signaling. When interpreting the responses to training, it is important to know, in particular when dealing with the issue of glucose uptake and related signaling pathways, when relative to the last bout, and preferably the last two bouts, the samples were collected to distinguish between acute and chronic training effects. Furthermore, exercise exposure can be considered the combined responses to intensity, bout duration, and bout frequency, where the product is usually considered to be total amount like total energy expenditure, but only a small number of intervention studies controlled for total work.

In regard to the key players of molecular signaling, the interplay of interacting pathways, such as the $\mathrm{Ca}^{2+} /$ calmodulin signaling pathway and the AMPK pathway, is still elusive. The inflammatory signaling pathways involving IKK/NF- $\kappa \mathrm{B}$ and the inflammasomes have not been sufficiently characterized in the context of the influence of acute as well as chronic exercise. The controversial results of the adiponectin exercise studies highlight potential species differences between men and mice and merit more mechanistic studies.

Furthermore, there is an intense need to detect to what extent the effects of physical exercise are independent of or explained by weight loss or change in body composition. Some of these questions require larger sample sizes and higher statistical power to quantify effects but also standardized methods for molecular measurements and high-quality study plans considering potential confounders.

\section{Conflict of Interests}

The authors declare that they have no conflict of interests. 


\section{References}

[1] A. V. Ardisson Korat, W. C. Willett, and F. B. Hu, "Diet, lifestyle, and genetic risk factors for type 2 diabetes: a review from the Nurses' Health Study, Nurses' Health Study 2, and Health Professionals' Follow-up study," Current Nutrition Reports, vol. 3, no. 4, pp. 345-354, 2014.

[2] R. Ringseis, K. Eder, F. C. Mooren, and K. Krüger, "Metabolic signals and innate immune activation in obesity and exercise," Exercise Immunology Review, vol. 21, pp. 58-68, 2015.

[3] Y. Hayashino, J. L. Jackson, T. Hirata et al., "Effects of exercise on C-reactive protein, inflammatory cytokine and adipokine in patients with type 2 diabetes: a meta-analysis of randomized controlled trials," Metabolism, vol. 63, no. 3, pp. 431-440, 2014.

[4] E. J. Henriksen, "Invited review: effects of acute exercise and exercise training on insulin resistance," Journal of Applied Physiology, vol. 93, no. 2, pp. 788-796, 2002.

[5] I. K. Martin, A. Katz, and J. Wahren, "Splanchnic and muscle metabolism during exercise in NIDDM patients," The American Journal of Physiology, vol. 269, no. 3, pp. E583-E590, 1995.

[6] M. C. F. Passos and M. C. Gonçalves, "Regulation of insulin sensitivity by adiponectin and its receptors in response to physical exercise," Hormone and Metabolic Research, vol. 46, no. 9, pp. 603-608, 2014.

[7] J.-A. Simoneau, J. H. Veerkamp, L. P. Turcotte, and D. E. Kelley, "Markers of capacity to utilize fatty acids in human skeletal muscle: relation to insulin resistance and obesity and effects of weight loss," The FASEB Journal, vol. 13, no. 14, pp. 2051-2060, 1999.

[8] B. Egan and J. R. Zierath, "Exercise metabolism and the molecular regulation of skeletal muscle adaptation," Cell Metabolism, vol. 17, no. 2, pp. 162-184, 2013.

[9] L. E. Gosselin, K. F. Kozlowski, L. Devinney-Boymel, and C. Hambridge, "Metabolic response of different high-intensity aerobic interval exercise protocols," Journal of Strength and Conditioning Research, vol. 26, no. 10, pp. 2866-2871, 2012.

[10] J. R. Silva, G. P. Nassis, and A. Rebelo, "Strength training in soccer with a specific focus on highly trained players," Sports Medicine-Open, vol. 1, article 17, 2015.

[11] P. D. Thompson, S. F. Crouse, B. Goodpaster, D. Kelley, N. Moyna, and L. Pescatello, "The acute versus the chronic response to exercise," Medicine and Science in Sports and Exercise, vol. 33, no. 6, pp. S438-S445, 2001.

[12] K. Cusi, K. Maezono, A. Osman et al., "Insulin resistance differentially affects the PI 3-kinase- and MAP kinase-mediated signaling in human muscle," The Journal of Clinical Investigation, vol. 105, no. 3, pp. 311-320, 2000.

[13] G. Perseghin, T. B. Price, K. F. Petersen et al., "Increased glucose transport-phosphorylation and muscle glycogen synthesis after exercise training in insulin-resistant subjects," The New England Journal of Medicine, vol. 335, no. 18, pp. 1357-1362, 1996.

[14] J. P. Kirwan, L. F. del Aguila, J. M. Hernandez et al., "Regular exercise enhances insulin activation of IRS-1-associated PI3kinase in human skeletal muscle," Journal of Applied Physiology, vol. 88, no. 2, pp. 797-803, 2000.

[15] K. F. Howlett, K. Sakamoto, H. Yu, L. J. Goodyear, and M. Hargreaves, "Insulin-stimulated insulin receptor substrate-2associated phosphatidylinositol 3-kinase activity is enhanced in human skeletal muscle after exercise," Metabolism: Clinical and Experimental, vol. 55, no. 8, pp. 1046-1052, 2006.

[16] A. Deshmukh, V. G. Coffey, Z. Zhong, A. V. Chibalin, J. A. Hawley, and J. R. Zierath, "Exercise-induced phosphorylation of the novel Akt substrates AS160 and filamin A in human skeletal muscle," Diabetes, vol. 55, no. 6, pp. 1776-1782, 2006.

[17] J. L. Treadway, D. E. James, E. Burcel, and N. B. Ruderman, "Effect of exercise on insulin receptor binding and kinase activity in skeletal muscle," The American Journal of PhysiologyEndocrinology and Metabolism, vol. 256, no. 1, pp. E138-E144, 1989.

[18] L. J. Goodyear, F. Giorgino, T. W. Balon, G. Condorelli, and R. J. Smith, "Effects of contractile activity on tyrosine phosphoproteins and PI 3-kinase activity in rat skeletal muscle," American Journal of Physiology_Endocrinology and Metabolism, vol. 268, no. 5, pp. 987-995, 1995.

[19] D. J. O'Gorman, H. K. R. Karlsson, S. McQuaid et al., "Exercise training increases insulin-stimulated glucose disposal and GLUT4 (SLC2A4) protein content in patients with type 2 diabetes," Diabetologia, vol. 49, no. 12, pp. 2983-2992, 2006.

[20] G. D. Wadley, N. Konstantopoulos, L. Macaulay et al., "Increased insulin-stimulated Akt pSer473 and cytosolic SHP2 protein abundance in human skeletal muscle following acute exercise and short-term training," Journal of Applied Physiology, vol. 102, no. 4, pp. 1624-1631, 2007.

[21] J. F. P. Wojtaszewski, B. F. Hansen, J. Gade et al., "Insulin signaling and insulin sensitivity after exercise in human skeletal muscle," Diabetes, vol. 49, no. 3, pp. 325-331, 2000.

[22] C. Frøsig and E. A. Richter, "Improved insulin sensitivity after exercise: focus on insulin signaling," Obesity, vol. 17, no. 3, pp. S15-S20, 2009.

[23] B. E. Kemp, K. I. Mitchelhill, D. Stapleton, B. J. Michell, Z.P. Chen, and L. A. Witters, "Dealing with energy demand: the AMP-activated protein kinase," Trends in Biochemical Sciences, vol. 24, no. 1, pp. 22-25, 1999.

[24] N. Musi, N. Fujii, M. F. Hirshman et al., "AMP-activated protein kinase (AMPK) is activated in muscle of subjects with type 2 diabetes during exercise," Diabetes, vol. 50, no. 5, pp. 921-927, 2001.

[25] A. Sriwijitkamol, D. K. Coletta, E. Wajcberg et al., "Effect of acute exercise on AMPK signaling in skeletal muscle of subjects with type 2 diabetes: a time-course and dose-response study," Diabetes, vol. 56, no. 3, pp. 836-848, 2007.

[26] B. Benziane, T. J. Burton, B. Scanlan et al., "Divergent cell signaling after short-term intensified endurance training in human skeletal muscle," American Journal of PhysiologyEndocrinology and Metabolism, vol. 295, no. 6, pp. E1427-E1438, 2008.

[27] B. Egan, B. P. Carson, P. M. Garcia-Roves et al., "Exercise intensity-dependent regulation of peroxisome proliferatoractivated receptor $\gamma$ coactivator- $1 \alpha$ mRNA abundance is associated with differential activation of upstream signalling kinases in human skeletal muscle," The Journal of Physiology, vol. 588, no. 10, pp. 1779-1790, 2010.

[28] M. J. Gibala, S. L. McGee, A. P. Garnham, K. F. Howlett, R. J. Snow, and M. Hargreaves, "Brief intense interval exercise activates AMPK and p38 MAPK signaling and increases the expression of PGC-1 $\alpha$ in human skeletal muscle," Journal of Applied Physiology, vol. 106, no. 3, pp. 929-934, 2009.

[29] K. Vissing, S. L. McGee, J. Farup, T. Kjølhede, M. H. Vendelbo, and N. Jessen, "Differentiated mTOR but not AMPK signaling after strength vs endurance exercise in training-accustomed individuals," Scandinavian Journal of Medicine and Science in Sports, vol. 23, no. 3, pp. 355-366, 2013.

[30] L. Luo, A.-M. Lu, Y. Wang et al., "Chronic resistance training activates autophagy and reduces apoptosis of muscle 
cells by modulating IGF-1 and its receptors, Akt/mTOR and Akt/FOXO3a signaling in aged rats," Experimental Gerontology, vol. 48, no. 4, pp. 427-436, 2013.

[31] V. C. Calegari, C. C. Zoppi, L. F. Rezende, L. R. Silveira, E. M. Carneiro, and A. C. Boschero, "Endurance training activates AMP-activated protein kinase, increases expression of uncoupling protein 2 and reduces insulin secretion from rat pancreatic islets," Journal of Endocrinology, vol. 208, no. 3, pp. 257-264, 2011.

[32] K. I. Stanford and L. J. Goodyear, "Exercise and type 2 diabetes: molecular mechanisms regulating glucose uptake in skeletal muscle," Advances in Physiology Education, vol. 38, no. 4, pp. 308-314, 2014.

[33] M. D. Nitert, T. Dayeh, P. Volkov et al., "Impact of an exercise intervention on DNA methylation in skeletal muscle from firstdegree relatives of patients with type 2 diabetes," Diabetes, vol. 61, no. 12, pp. 3322-3332, 2012.

[34] A. J. Rose, B. Kiens, and E. A. Richter, " $\mathrm{Ca}^{2+}$-calmodulindependent protein kinase expression and signalling in skeletal muscle during exercise," Journal of Physiology, vol. 574, no. 3, pp. 889-903, 2006.

[35] A. Combes, J. Dekerle, N. Webborn, P. Watt, V. Bougault, and F. N. Daussin, "Exercise-induced metabolic fluctuations influence AMPK, p38-MAPK and CaMKII phosphorylation in human skeletal muscle," Physiological Reports, vol. 3, Article ID e12462, 2015.

[36] A. Katta, S. Kakarla, M. Wu et al., "Altered regulation of contraction-induced Akt/mTOR/p70S6k pathway signaling in skeletal muscle of the obese Zucker rat," Experimental Diabetes Research, vol. 2009, Article ID 384683, 9 pages, 2009.

[37] A. Philp, D. L. Hamilton, and K. Baar, "Signals mediating skeletal muscle remodeling by resistance exercise: PI3-kinase independent activation of mTORC1," Journal of Applied Physiology, vol. 110, no. 2, pp. 561-568, 1985.

[38] C. A. Stuart, M. E. A. Howell, J. D. Baker et al., "Cycle training increased glut4 and activation of mammalian target of rapamycin in fast twitch muscle fibers," Medicine and Science in Sports and Exercise, vol. 42, no. 1, pp. 96-106, 2010.

[39] D. M. Camera, J. Edge, M. J. Short, J. A. Hawley, and V. G. Coffey, "Early time course of akt phosphorylation after endurance and resistance exercise," Medicine and Science in Sports and Exercise, vol. 42, no. 10, pp. 1843-1852, 2010.

[40] H. C. Dreyer, S. Fujita, J. G. Cadenas, D. L. Chinkes, E. Volpi, and B. B. Rasmussen, "Resistance exercise increases AMPK activity and reduces $4 \mathrm{E}-\mathrm{BP} 1$ phosphorylation and protein synthesis in human skeletal muscle," Journal of Physiology, vol. 576, no. 2, pp. 613-624, 2006.

[41] D. M. Thomson, C. A. Fick, and S. E. Gordon, "AMPK activation attenuates $\mathrm{S} 6 \mathrm{~K} 1,4 \mathrm{E}-\mathrm{BP} 1$, and eEF2 signaling responses to highfrequency electrically stimulated skeletal muscle contractions," Journal of Applied Physiology, vol. 104, no. 3, pp. 625-632, 2008.

[42] K. Inoki, H. Ouyang, T. Zhu et al., "TSC2 integrates Wnt and energy signals via a coordinated phosphorylation by AMPK and GSK3 to regulate cell growth," Cell, vol. 126, no. 5, pp. 955-968, 2006.

[43] H. Mascher, B. Ekblom, O. Rooyackers, and E. Blomstrand, "Enhanced rates of muscle protein synthesis and elevated mTOR signalling following endurance exercise in human subjects," Acta Physiologica, vol. 202, no. 2, pp. 175-184, 2011.

[44] S. Fujita, B. B. Rasmussen, J. G. Cadenas et al., "Aerobic exercise overcomes the age-related insulin resistance of muscle protein metabolism by improving endothelial function and Akt/mammalian target of rapamycin signaling," Diabetes, vol. 56, no. 6, pp. 1615-1622, 2007.

[45] J. K. Pugh, S. H. Faulkner, A. P. Jackson, J. A. King, and M. A. Nimmo, "Acute molecular responses to concurrent resistance and high-intensity interval exercise in untrained skeletal muscle," Physiological Reports, vol. 3, no. 4, Article ID e12364, 2015.

[46] B. A. Edgett, M. L. Fortner, A. Bonen, and B. J. Gurd, "Mammalian target of rapamycin pathway is up-regulated by both acute endurance exercise and chronic muscle contraction in rat skeletal muscle," Applied Physiology, Nutrition and Metabolism, vol. 38, no. 8, pp. 862-869, 2013.

[47] S. J. Maarbjerg, L. Sylow, and E. A. Richter, "Current understanding of increased insulin sensitivity after exerciseemerging candidates," Acta Physiologica, vol. 202, no. 3, pp. 323335, 2011.

[48] L. Sylow, M. Kleinert, C. Pehmøller et al., "Akt and Racl signaling are jointly required for insulin-stimulated glucose uptake in skeletal muscle and downregulated in insulin resistance," Cellular Signalling, vol. 26, no. 2, pp. 323-331, 2014.

[49] C. M. Castorena, E. B. Arias, N. Sharma, and G. D. Cartee, "Postexercise improvement in insulin-stimulated glucose uptake occurs concomitant with greater AS160 phosphorylation in muscle from normal and insulin-resistant rats," Diabetes, vol. 63, no. 7, pp. 2297-2308, 2014.

[50] K. Sakamoto, M. F. Hirshman, W. G. Aschenbach, and L. J. Goodyear, "Contraction regulation of Akt in rat skeletal muscle," The Journal of Biological Chemistry, vol. 277, no. 14, pp. 11910-11917, 2002.

[51] J. F. P. Wojtaszewski, Y. Higaki, M. F. Hirshman et al., "Exercise modulates postreceptor insulin signaling and glucose transport in muscle-specific insulin receptor knockout mice," Journal of Clinical Investigation, vol. 104, no. 9, pp. 1257-1264, 1999.

[52] L. A. Consitt, J. Van Meter, C. A. Newton et al., "Impairments in site-specific AS160 phosphorylation and effects of exercise training," Diabetes, vol. 62, no. 10, pp. 3437-3447, 2013.

[53] I. R. Ritchie, D. C. Wright, and D. J. Dyck, "Adiponectin is not required for exercise training-induced improvements in glucose and insulin tolerance in mice," Physiological Reports, vol. 2, no. 9, Article ID e12146, 2014.

[54] M. H. Vendelbo, A. B. Møller, J. T. Treebak et al., "Sustained AS160 and TBC1D1 phosphorylations in human skeletal muscle 30 min after a single bout of exercise," Journal of Applied Physiology, vol. 117, no. 3, pp. 289-296, 2014.

[55] J. T. Treebak, J. B. Birk, A. J. Rose, B. Kiens, E. A. Richter, and J. F. P. Wojtaszewski, "AS160 phosphorylation is associated with activation of $\alpha 2 \beta 2 \gamma 1$ - but not $\alpha 2 \beta 2 \gamma 3$-AMPK trimeric complex in skeletal muscle during exercise in humans," The American Journal of Physiology -Endocrinology and Metabolism, vol. 292, no. 3, pp. E715-E722, 2007.

[56] J. T. Treebak, C. Frøsig, C. Pehmøller et al., "Potential role of TBC1D4 in enhanced post-exercise insulin action in human skeletal muscle," Diabetologia, vol. 52, no. 5, pp. 891-900, 2009.

[57] M. D. Bruss, E. B. Arias, G. E. Lienhard, and G. D. Cartee, "Increased phosphorylation of Akt substrate of $160 \mathrm{kDa}$ (AS160) in rat skeletal muscle in response to insulin or contractile activity," Diabetes, vol. 54, no. 1, pp. 41-50, 2005.

[58] L. Sylow, L. L. Møller, M. Kleinert, E. A. Richter, and T. E. Jensen, "Racl-a novel regulator of contraction-stimulated glucose uptake in skeletal muscle," Experimental Physiology, vol. 99, no. 12, pp. 1574-1580, 2014. 
[59] L. Sylow, T. E. Jensen, M. Kleinert et al., "Racl is a novel regulator of contraction-stimulated glucose uptake in skeletal muscle," Diabetes, vol. 62, no. 4, pp. 1139-1151, 2013.

[60] L. Sylow, L. L. V. Møller, M. Kleinert, E. A. Richter, and T. E. Jensen, "Stretch-stimulated glucose transport in skeletal muscle is regulated by Racl," Journal of Physiology, vol. 593, no. 3, pp. 645-656, 2015.

[61] N. Kawanishi, H. Yano, Y. Yokogawa, and K. Suzuki, "Exercise training inhibits inflammation in adipose tissue via both suppression of macrophage infiltration and acceleration of phenotypic switching from M1 to M2 macrophages in high-fatdiet-induced obese mice," Exercise Immunology Review, vol. 16, pp. 105-118, 2010.

[62] N. Kawanishi, T. Mizokami, H. Yano, and K. Suzuki, "Exercise attenuates $\mathrm{M} 1$ macrophages and $\mathrm{CD}^{+} \mathrm{T}$ cells in the adipose tissue of obese mice," Medicine and Science in Sports and Exercise, vol. 45, no. 9, pp. 1684-1693, 2013.

[63] A. Sriwijitkamol, C. Christ-Roberts, R. Berria et al., "Reduced skeletal muscle inhibitor of $\kappa \mathrm{B} \beta$ content is associated with insulin resistance in subjects with type 2 diabetes: reversal by exercise training," Diabetes, vol. 55, no. 3, pp. 760-767, 2006.

[64] G. I. Lancaster, Q. Khan, P. Drysdale et al., "The physiological regulation of toll-like receptor expression and function in humans," The Journal of Physiology, vol. 563, no. 3, pp. 945-955, 2005.

[65] M. Oliveira and M. Gleeson, "The influence of prolonged cycling on monocyte Toll-like receptor 2 and 4 expression in healthy men," European Journal of Applied Physiology, vol. 109, no. 2, pp. 251-257, 2010.

[66] P. Rodriguez-Miguelez, R. Fernandez-Gonzalo, M. Almar et al., "Role of Toll-like receptor 2 and 4 signaling pathways on the inflammatory response to resistance training in elderly subjects," Age, vol. 36, article 9734, 2014.

[67] G. da Luz, M. J. S. Frederico, S. da Silva et al., "Endurance exercise training ameliorates insulin resistance and reticulum stress in adipose and hepatic tissue in obese rats," European Journal of Applied Physiology, vol. 111, no. 9, pp. 2015-2023, 2011.

[68] C. Medeiros, M. J. Frederico, G. da Luz et al., "Exercise training reduces insulin resistance and upregulates the mTOR/p70S6k pathway in cardiac muscle of diet-induced obesity rats," Journal of Cellular Physiology, vol. 226, no. 3, pp. 666-674, 2011.

[69] A. G. Oliveira, B. M. Carvalho, N. Tobar et al., "Physical exercise reduces circulating lipopolysaccharide and TLR4 activation and improves insulin signaling in tissues of DIO rats," Diabetes, vol. 60, no. 3, pp. 784-796, 2011.

[70] D. Lyngsø, L. Simonsen, and J. Bülow, "Interleukin-6 production in human subcutaneous abdominal adipose tissue: the effect of exercise," Journal of Physiology, vol. 543, no. 1, pp. 373378, 2002.

[71] C. P. Fischer, "Interleukin-6 in acute exercise and training: what is the biological relevance?" Exercise Immunology Review, vol. 12, pp. 6-33, 2006.

[72] K. Ostrowski, T. Rohde, M. Zacho, S. Asp, and B. K. Pedersen, "Evidence that interleukin-6 is produced in human skeletal muscle during prolonged running," The Journal of Physiology, vol. 508, no. 3, pp. 949-953, 1998.

[73] M. Leggate, M. A. Nowell, S. A. Jones, and M. A. Nimmo, “The response of interleukin- 6 and soluble interleukin-6 receptor isoforms following intermittent high intensity and continuous moderate intensity cycling," Cell Stress and Chaperones, vol. 15, no. 6 , pp. 827-833, 2010.
[74] L. Castellani, C. G. Perry, R. E. MacPherson et al., "Exercisemediated IL-6 signaling occurs independent of inflammation and is amplified by training in mouse adipose tissue," Journal of Applied Physiology, vol. 119, pp. 1347-1354, 2015.

[75] R. E. Macpherson, J. S. Huber, S. Frendo-Cumbo, J. A. Simpson, and D. C. Wright, "Adipose tissue insulin action and IL-6 signaling after exercise in obese mice," Medicine \& Science in Sports \& Exercise, vol. 47, no. 10, pp. 2034-2042, 2015.

[76] A. M. W. Petersen and B. K. Pedersen, "The anti-inflammatory effect of exercise," Journal of Applied Physiology, vol. 98, no. 4, pp. 1154-1162, 2005.

[77] E. Hopps, B. Canino, and G. Caimi, "Effects of exercise on inflammation markers in type 2 diabetic subjects," Acta Diabetologica, vol. 48, no. 3, pp. 183-189, 2011.

[78] N. P. Kadoglou, D. Perrea, F. Iliadis, N. Angelopoulou, C. Liapis, and M. Alevizos, "Exercise reduces resistin and inflammatory cytokines in patients with type 2 diabetes," Diabetes Care, vol. 30, no. 3, pp. 719-721, 2007.

[79] L. Leick, B. Lindegaard, D. Stensvold, P. Plomgaard, B. Saltin, and H. Pilegaard, "Adipose tissue interleukin-18 mRNA and plasma interleukin-18: effect of obesity and exercise," Obesity, vol. 15, no. 2, pp. 356-363, 2007.

[80] C. Mardare, K. Krüger, G. Liebisch et al., "Endurance and resistance training affect high fat diet-induced increase of ceramides, inflammasome expression, and systemic inflammation in mice," Journal of Diabetes Research, vol. 2016, Article ID 4536470, 13 pages, 2016.

[81] M. Whitham, M. H. S. Chan, M. Pal et al., "Contractioninduced interleukin-6 gene transcription in skeletal muscle is regulated by c-Jun terminal kinase/activator protein-1," Journal of Biological Chemistry, vol. 287, no. 14, pp. 10771-10779, 2012.

[82] D. Aronson, M. D. Boppart, S. D. Dufresne, R. A. Fielding, and L. J. Goodyear, "Exercise stimulates c-Jun NH2 kinase activity and c-Jun transcriptional activity in human skeletal muscle," Biochemical and Biophysical Research Communications, vol. 251, no. 1, pp. 106-110, 1998.

[83] M. D. Boppart, S. Asp, J. F. P. Wojtaszewski, R. A. Fielding, T. Mohr, and L. J. Goodyear, "Marathon running transiently increases c-Jun NH2-terminal kinase and p38 $\gamma$ activities in human skeletal muscle," The Journal of Physiology, vol. 526, no. 3, pp. 663-669, 2000.

[84] A. J. Galpin, A. C. Fry, L. Z. F. Chiu, D. B. Thomason, and B. K. Schilling, "High-power resistance exercise induces MAPK phosphorylation in weightlifting trained men," Applied Physiology, Nutrition and Metabolism, vol. 37, no. 1, pp. 80-87, 2012.

[85] E. Passos, C. D. Pereira, I. O. Gonçalves et al., "Role of physical exercise on hepatic insulin, glucocorticoid and inflammatory signaling pathways in an animal model of non-alcoholic steatohepatitis," Life Sciences, vol. 123, pp. 51-60, 2015.

[86] J. Jürimäe, P. Hofmann, T. Jürimäe et al., "Plasma adiponectin response to sculling exercise at individual anaerobic threshold in college level male rowers," International Journal of Sports Medicine, vol. 27, no. 4, pp. 272-277, 2006.

[87] C. Punyadeera, A. H. G. Zorenc, R. Koopman et al., "The effects of exercise and adipose tissue lipolysis on plasma adiponectin concentration and adiponectin receptor expression in human skeletal muscle," European Journal of Endocrinology, vol. 152, no. 3, pp. 427-436, 2005.

[88] A. D. Kriketos, S. K. Gan, A. M. Poynten, S. M. Furler, D. J. Chisholm, and L. V. Campbell, "Exercise increases adiponectin 
levels and insulin sensitivity in humans," Diabetes Care, vol. 27, no. 2, pp. 629-630, 2004.

[89] S. Lim, H. C. Sung, I.-K. Jeong et al., "Insulin-sensitizing effects of exercise on adiponectin and retinol-binding protein4 concentrations in young and middle-aged women," Journal of Clinical Endocrinology and Metabolism, vol. 93, no. 6, pp. 22632268, 2008.

[90] V. B. O’Leary, C. M. Marchetti, R. K. Krishnan, B. P. Stetzer, F. Gonzalez, and J. P. Kirwan, "Exercise-induced reversal of insulin resistance in obese elderly is associated with reduced visceral fat," Journal of Applied Physiology, vol. 100, no. 5, pp. 1584-1589, 2006.

[91] K. A. Simpson and M. A. F. Singh, "Effects of exercise on adiponectin: a systematic review," Obesity, vol. 16, no. 2, pp. 241256, 2008.

[92] T. Kondo, I. Kobayashi, and M. Murakami, "Effect of exercise on circulating adipokine levels in obese young women," Endocrine Journal, vol. 53, no. 2, pp. 189-195, 2006.

[93] I. G. Fatouros, S. Tournis, D. Leontsini et al., "Leptin and adiponectin responses in overweight inactive elderly following resistance training and detraining are intensity related," Journal of Clinical Endocrinology and Metabolism, vol. 90, no. 11, pp. 5970-5977, 2005.

[94] J. K. Cho, S. Kim, H. R. Hong, J. H. Yoon, and H. Kang, "Exercise training improves whole body insulin resistance via adiponectin receptor 1," International Journal of Sports Medicine, 2016.

[95] C. Frøsig, A. J. Rose, J. T. Treebak, B. Kiens, E. A. Richter, and J. F. P. Wojtaszewski, "Effects of endurance exercise training on insulin signaling in human skeletal muscle: Interactions at the level of phosphatidylinositol 3-kinase, Akt, and AS160," Diabetes, vol. 56, no. 8, pp. 2093-2102, 2007.

[96] M. K. Holten, M. Zacho, M. Gaster, C. Juel, J. F. P. Wojtaszewski, and F. Dela, "Strength training increases insulin-mediated glucose uptake, GLUT4 content, and insulin signaling in skeletal muscle in patients with type 2 diabetes," Diabetes, vol. 53 , no. 2 , pp. 294-305, 2004.

[97] N. Fujii, M. F. Hirshman, E. M. Kane et al., "AMP-activated protein kinase $\alpha 2$ activity is not essential for contraction- and hyperosmolarity-induced glucose transport in skeletal muscle," Journal of Biological Chemistry, vol. 280, no. 47, pp. 3903339041, 2005.

[98] J. Jeppesen, S. J. Maarbjerg, A. B. Jordy et al., "LKB1 regulates lipid oxidation during exercise independently of AMPK," Diabetes, vol. 62, no. 5, pp. 1490-1499, 2013.

[99] N. Lefort, E. St-Amand, S. Morasse, C. H. Côté, and A. Marette, "The $\alpha$-subunit of AMPK is essential for submaximal contraction-mediated glucose transport in skeletal muscle in vitro," The American Journal of Physiology-Endocrinology and Metabolism, vol. 295, no. 6, pp. E1447-E1454, 2008.

[100] K. Sakamoto, A. McCarthy, D. Smith et al., "Deficiency of LKB1 in skeletal muscle prevents AMPK activation and glucose uptake during contraction," The EMBO Journal, vol. 24, no. 10, pp. 1810-1820, 2005.

[101] L. Sylow, T. E. Jensen, M. Kleinert et al., "Racl signaling is required for insulin-stimulated glucose uptake and is dysregulated in insulin-resistant murine and human skeletal muscle," Diabetes, vol. 62, no. 6, pp. 1865-1875, 2013.

[102] C. A. Witczak, N. Fujii, M. F. Hirshman, and L. J. Goodyear, " $\mathrm{Ca}^{2+} /$ calmodulin-dependent protein kinase kinase- $\alpha$ regulates skeletal muscle glucose uptake independent of AMP-activated protein kinase and Akt activation," Diabetes, vol. 56, no. 5, pp. 1403-1409, 2007.
[103] C. A. Witczak, N. Jessen, D. M. Warro et al., "CaMKII regulates contraction- but not insulin-induced glucose uptake in mouse skeletal muscle," American Journal of PhysiologyEndocrinology and Metabolism, vol. 298, no. 6, pp. E1150-E1160, 2010.

[104] C. Keller, A. Steensberg, H. Pilegaard et al., "Transcriptional activation of the IL- 6 gene in human contracting skeletal muscle: influence of muscle glycogen content," The FASEB Journal, vol. 15, no. 14, pp. 2748-2750, 2001.

[105] M. A. Febbraio, N. Hiscock, M. Sacchetti, C. P. Fischer, and B. K. Pedersen, "Interleukin-6 is a novel factor mediating glucose homeostasis during skeletal muscle contraction," Diabetes, vol. 53, no. 7, pp. 1643-1648, 2004.

[106] K. Ostrowski, T. Rohde, S. Asp, P. Schjerling, and B. K. Pedersen, "Pro- and anti-inflammatory cytokine balance in strenuous exercise in humans," The Journal of Physiology, vol. 515, no. 1, pp. 287-291, 1999.

[107] R. L. Starkie, J. Rolland, D. J. Angus, M. J. Anderson, and M. A. Febbraio, "Circulating monocytes are not the source of elevations in plasma IL- 6 and TNF- $\alpha$ levels after prolonged running," American Journal of Physiology-Cell Physiology, vol. 280, no. 4, pp. C769-C774, 2001.

[108] K. Suzuki, M. Yamada, S. Kurakake et al., "Circulating cytokines and hormones with immunosuppressive but neutrophil-priming potentials rise after endurance exercise in humans," European Journal of Applied Physiology, vol. 81, no. 4, pp. 281-287, 2000.

[109] S. R. Gray, G. Baker, A. Wright, C. F. Fitzsimons, N. Mutrie, and M. A. Nimmo, "The effect of a 12 week walking intervention on markers of insulin resistance and systemic inflammation," Preventive Medicine, vol. 48, no. 1, pp. 39-44, 2009.

[110] M. Roden, "Exercise in type 2 diabetes: to resist or to endure?" Diabetologia, vol. 55, no. 5, pp. 1235-1239, 2012.

[111] K. S. C. Röckl, C. A. Witczak, and L. J. Goodyear, "Signaling mechanisms in skeletal muscle: acute responses and chronic adaptations to exercise," IUBMB Life, vol. 60, no. 3, pp. 145-153, 2008.

[112] J. R. Zierath, A. Krook, and H. Wallberg-Henriksson, "Insulin action and insulin resistance in human skeletal muscle," Diabetologia, vol. 43, no. 7, pp. 821-835, 2000.

[113] M. Björnholm, Y. Kawano, M. Lehtihet, and J. R. Zierath, "Insulin receptor substrate-1 phosphorylation and phosphatidylinositol 3-kinase activity in skeletal muscle from NIDDM subjects after in vivo insulin stimulation," Diabetes, vol. 46, no. 3, pp. 524-527, 1997.

[114] A. Krook, R. A. Roth, X. J. Jiang, J. R. Zierath, and H. WallbergHenriksson, "Insulin-stimulated Akt kinase activity is reduced in skeletal muscle from NIDDM subjects," Diabetes, vol. 47, no. 8, pp. 1281-1286, 1998.

[115] J. W. Ryder, J. Yang, D. Galuska et al., "Use of a novel impermeable biotinylated photolabeling reagent to assess insulinand hypoxia-stimulated cell surface GLUT4 content in skeletal muscle from type 2 diabetic patients," Diabetes, vol. 49 , no. 4 , pp. 647-654, 2000.

[116] J. R. Zierath, L. He, A. Gumà, E. Odegaard Wahlström, A. Klip, and H. Wallberg-Henriksson, "Insulin action on glucose transport and plasma membrane GLUT4 content in skeletal muscle from patients with NIDDM," Diabetologia, vol. 39, no. 10, pp. 1180-1189, 1996.

[117] V. A. Lira, C. R. Benton, Z. Yan, and A. Bonen, "PGC- $1 \alpha$ regulation by exercise training and its influences on muscle 
function and insulin sensitivity," The American Journal of Physiology-Endocrinology and Metabolism, vol. 299, no. 2, pp. E145-E161, 2010.

[118] B. B. Kahn, T. Alquier, D. Carling, and D. G. Hardie, "AMPactivated protein kinase: ancient energy gauge provides clues to modern understanding of metabolism," Cell Metabolism, vol. 1, no. 1, pp. 15-25, 2005.

[119] D. R. Park, K. H. Park, B. J. Kim, C. S. Yoon, and U. H. Kim, "Exercise ameliorates insulin resistance via $\mathrm{Ca}^{2+}$ signals distinct from those of insulin for GLUT4 translocation in skeletal muscles," Diabetes, vol. 64, no. 4, pp. 1224-1234, 2015.

[120] J. T. Lanner, J. D. Bruton, A. Katz, and H. Westerblad, " $\mathrm{Ca}^{2+}$ and insulin-mediated glucose uptake," Current Opinion in Pharmacology, vol. 8, no. 3, pp. 339-345, 2008.

[121] D. C. Wright, K. A. Hucker, J. O. Holloszy, and D. H. Han, "Ca ${ }^{2+}$ and AMPK both mediate stimulation of glucose transport by muscle contractions," Diabetes, vol. 53, no. 2, pp. 330-335, 2004.

[122] R. Rashmi, C. DeSelm, C. Helms et al., "AKT inhibitors promote cell death in cervical cancer through disruption of mTOR signaling and glucose uptake," PLoS ONE, vol. 9, no. 4, Article ID e92948, 2014.

[123] C. L. Buller, R. D. Loberg, M.-H. Fan et al., "A GSK3/TSC2/mTOR pathway regulates glucose uptake and GLUT1 glucose transporter expression," The American Journal of Physiology-Cell Physiology, vol. 295, no. 3, pp. C836-C843, 2008.

[124] M. J. Pereira, J. Palming, M. Rizell et al., "mTOR inhibition with rapamycin causes impaired insulin signalling and glucose uptake in human subcutaneous and omental adipocytes," Molecular and Cellular Endocrinology, vol. 355, no. 1, pp. 96-105, 2012.

[125] M. Kleinert, L. Sylow, D. J. Fazakerley et al., "Acute mTOR inhibition induces insulin resistance and alters substrate utilization in vivo," Molecular Metabolism, vol. 3, no. 6, pp. 630-641, 2014.

[126] M. Fraenkel, M. Ketzinel-Gilad, Y. Ariav et al., "mTOR inhibition by rapamycin prevents $\beta$-cell adaptation to hyperglycemia and exacerbates the metabolic state in type 2 diabetes," Diabetes, vol. 57, no. 4, pp. 945-957, 2008.

[127] S. C. Bodine, T. N. Stitt, M. Gonzalez et al., "Akt/mTOR pathway is a crucial regulator of skeletal muscle hypertrophy and can prevent muscle atrophy in vivo," Nature Cell Biology, vol. 3, no. 11, pp. 1014-1019, 2001.

[128] M. Sandri, "Signaling in muscle atrophy and hypertrophy," Physiology, vol. 23, no. 3, pp. 160-170, 2008.

[129] S. Klossner, A.-C. Durieux, D. Freyssenet, and M. Flueck, "Mechano-transduction to muscle protein synthesis is modulated by FAK," European Journal of Applied Physiology, vol. 106, no. 3, pp. 389-398, 2009.

[130] K. Huang and D. C. Fingar, "Growing knowledge of the mTOR signaling network," Seminars in Cell and Developmental Biology, vol. 36, pp. 79-90, 2014.

[131] H. F. Kramer, C. A. Witczak, E. B. Taylor, N. Fujii, M. F. Hirshman, and L. J. Goodyear, "AS160 regulates insulinand contraction-stimulated glucose uptake in mouse skeletal muscle," The Journal of Biological Chemistry, vol. 281, no. 42, pp. 31478-31485, 2006.

[132] K. Vichaiwong, S. Purohit, D. An et al., "Contraction regulates site-specific phosphorylation of TBC1D1 in skeletal muscle," Biochemical Journal, vol. 431, no. 2, pp. 311-320, 2010.

[133] C. Y. Christ-Roberts, T. Pratipanawatr, W. Pratipanawatr, R. Berria, R. Belfort, and L. J. Mandarino, "Increased insulin receptor signaling and glycogen synthase activity contribute to the synergistic effect of exercise on insulin action," Journal of Applied Physiology, vol. 95, no. 6, pp. 2519-2529, 2003.

[134] L. JeBailey, O. Wanono, W. Niu, J. Roessler, A. Rudich, and A. Klip, "Ceramide- and oxidant-induced insulin resistance involve loss of insulin-dependent Rac-activation and actin remodeling in muscle cells," Diabetes, vol. 56, no. 2, pp. 394403, 2007.

[135] H. Cho, J. Mu, J. K. Kim et al., "Insulin resistance and a diabetes mellitus-like syndrome in mice lacking the protein kinase Akt2 (РКB $\beta)$," Science, vol. 292, no. 5522, pp. 1728-1731, 2001.

[136] P. H. Albers, A. J. T. Pedersen, J. B. Birk et al., "Human muscle fiber type-specific insulin signaling: impact of obesity and type 2 diabetes," Diabetes, vol. 64, no. 2, pp. 485-497, 2015.

[137] O. S. Kwon, R. E. Tanner, K. M. Barrows et al., "MyD88 regulates physical inactivity-induced skeletal muscle inflammation, ceramide biosynthesis signaling, and glucose intolerance," The American Journal of Physiology-Endocrinology and Metabolism, vol. 309, no. 1, pp. E11-E21, 2015.

[138] S. Akira and S. Sato, "Toll-like receptors and their signaling mechanisms," Scandinavian Journal of Infectious Diseases, vol. 35, no. 9, pp. 555-562, 2003.

[139] L. Chen, R. Chen, H. Wang, and F. Liang, "Mechanisms linking inflammation to insulin resistance," International Journal of Endocrinology, vol. 2015, Article ID 508409, 9 pages, 2015.

[140] A. Steensberg, C. P. Fischer, C. Keller, K. Møller, and B. K. Pedersen, "IL-6 enhances plasma IL-1ra, IL-10, and cortisol in humans," The American Journal of Physiology-Endocrinology and Metabolism, vol. 285, no. 2, pp. E433-E437, 2003.

[141] H. Wen, E. A. Miao, and J. P.-Y. Ting, "Mechanisms of NODlike receptor-associated inflammasome activation," Immunity, vol. 39, no. 3, pp. 432-441, 2013.

[142] J. Jager, T. Grémeaux, M. Cormont, Y. Le Marchand-Brustel, and J.-F. Tanti, "Interleukin- $1 \beta$-induced insulin resistance in adipocytes through down-regulation of insulin receptor substrate-1 expression," Endocrinology, vol. 148, no. 1, pp. 241251, 2007.

[143] C. Herder, E. Dalmas, M. Böni-Schnetzler, and M. Y. Donath, "The IL-1 pathway in type 2 diabetes and cardiovascular complications," Trends in Endocrinology \& Metabolism, vol. 26, no. 10, pp. 551-563, 2015.

[144] H. F. Kramer and L. J. Goodyear, "Exercise, MAPK, and NF- $\kappa$ B signaling in skeletal muscle," Journal of Applied Physiology, vol. 103, no. 1, pp. 388-395, 2007.

[145] Z. Gao, D. Hwang, F. Bataille et al., "Serine phosphorylation of insulin receptor substrate 1 by inhibitor $\kappa \mathrm{B}$ kinase complex," The Journal of Biological Chemistry, vol. 277, no. 50, pp. 48115-48121, 2002.

[146] K. Müssig, H. Staiger, H. Fiedler et al., "Shp2 is required for protein kinase C-dependent phosphorylation of serine 307 in insulin receptor substrate-1," Journal of Biological Chemistry, vol. 280, no. 38, pp. 32693-32699, 2005.

[147] K. Müssig, H. Fiedler, H. Staiger et al., "Insulin-induced stimulation of JNK and the PI 3-kinase/mTOR pathway leads to phosphorylation of serine 318 of IRS-1 in C2C12 myotubes," Biochemical and Biophysical Research Communications, vol. 335, no. 3, pp. 819-825, 2005.

[148] E. Kefaloyianni, C. Gaitanaki, and I. Beis, "ERK1/2 and p38MAPK signalling pathways, through MSK1, are involved in NF$\kappa \mathrm{B}$ transactivation during oxidative stress in skeletal myoblasts," Cellular Signalling, vol. 18, no. 12, pp. 2238-2251, 2006. 
[149] M. Karin and E. Gallagher, "From JNK to pay dirt: jun kinases, their biochemistry, physiology and clinical importance," IUBMB Life, vol. 57, no. 4-5, pp. 283-295, 2005.

[150] T. Kadowaki, K. Hara, T. Yamauchi, Y. Terauchi, K. Tobe, and R. Nagai, "Molecular mechanism of insulin resistance and obesity," Experimental Biology and Medicine, vol. 228, no. 10, pp. 1111-1117, 2003.

[151] M. J. Yoon, G. Y. Lee, J. J. Chung, Y. H. Ahn, S. H. Hong, and J. B. Kim, "Adiponectin increases fatty acid oxidation in skeletal muscle cells by sequential activation of AMP-activated protein kinase, p38 mitogen-activated protein kinase, and peroxisome proliferator-activated receptor alpha," Diabetes, vol. 55, no. 9, pp. 2562-2570, 2006.

[152] X. Mao, C. K. Kikani, R. A. Riojas et al., "APPL1 binds to adiponectin receptors and mediates adiponectin signalling and function," Nature Cell Biology, vol. 8, no. 5, pp. 516-523, 2006.

[153] C. Herder, M. Carstensen, and D. M. Ouwens, "Antiinflammatory cytokines and risk of type 2 diabetes," Diabetes, Obesity and Metabolism, vol. 15, no. 3, pp. 39-50, 2013.

[154] K. Ohashi, R. Shibata, T. Murohara, and N. Ouchi, "Role of antiinflammatory adipokines in obesity-related diseases," Trends in Endocrinology and Metabolism, vol. 25, no. 7, pp. 348-355, 2014.

[155] M. Okada-Iwabu, T. Yamauchi, M. Iwabu et al., "A smallmolecule AdipoR agonist for type 2 diabetes and short life in obesity," Nature, vol. 503, no. 7477, pp. 493-499, 2013.

[156] L. M. Belalcazar, W. Lang, S. M. Haffner et al., "Improving adiponectin levels in individuals with diabetes and obesity: insights from Look AHEAD," Diabetes Care, vol. 38, no. 8, pp. 1544-1550, 2015.

[157] L. M. Belalcazar, W. Lang, S. M. Haffner et al., "Adiponectin and the mediation of HDL-cholesterol change with improved lifestyle: the look AHEAD study," Journal of Lipid Research, vol. 53, no. 12, pp. 2726-2733, 2012.

[158] Y. Deng and P. E. Scherer, "Adipokines as novel biomarkers and regulators of the metabolic syndrome," Annals of the New York Academy of Sciences, vol. 1212, pp. E1-E19, 2010.

[159] C. Herder, M. Peltonen, P.-A. Svensson et al., "Adiponectin and bariatric surgery: associations with diabetes and cardiovascular disease in the Swedish Obese Subjects Study," Diabetes Care, vol. 37, no. 5, pp. 1401-1409, 2014.

[160] B. K. Pedersen and H. Bruunsgaard, "Possible beneficial role of exercise in modulating low-grade inflammation in the elderly," Scandinavian Journal of Medicine and Science in Sports, vol. 13, no. 1, pp. 56-62, 2003.

[161] C. Herder, J. Baumert, A. Zierer et al., "Immunological and cardiometabolic risk factors in the prediction of type 2 diabetes and coronary events: MONICA/KORA Augsburg case-cohort study," PLoS ONE, vol. 6, no. 6, Article ID e19852, 2011.

[162] C. Herder, J. Baumert, B. Thorand et al., "Chemokines as risk factors for type 2 diabetes: results from the MONICA/KORA Augsburg study, 1984-2002," Diabetologia, vol. 49, no. 5, pp. 921-929, 2006.

[163] C. Herder, M. Peltonen, W. Koenig et al., "Anti-inflammatory effect of lifestyle changes in the Finnish Diabetes Prevention Study," Diabetologia, vol. 52, no. 3, pp. 433-442, 2009.

[164] F. Ribeiro, A. J. Alves, J. A. Duarte, and J. Oliveira, "Is exercise training an effective therapy targeting endothelial dysfunction and vascular wall inflammation?" International Journal of Cardiology, vol. 141, no. 3, pp. 214-221, 2010.

[165] P. L. Gordon, E. Vannier, K. Hamada et al., "Resistance training alters cytokine gene expression in skeletal muscle of adults with type 2 diabetes," International Journal of Immunopathology and Pharmacology, vol. 19, no. 4, pp. 739-749, 2006.

[166] G. S. Hotamisligil, "The role of TNF $\alpha$ and TNF receptors in obesity and insulin resistance," Journal of Internal Medicine, vol. 245, no. 6, pp. 621-625, 1999.

[167] R. Halse, S. L. Pearson, J. G. McCormack, S. J. Yeaman, and R. Taylor, "Effects of tumor necrosis factor- $\alpha$ on insulin action in cultured human muscle cells," Diabetes, vol. 50, no. 5, pp. 1102 1109, 2001.

[168] J. M. Youd, S. Rattigan, and M. G. Clark, "Acute impairment of insulin-mediated capillary recruitment and glucose uptake rat skeletal muscle vivo by TNF- $\alpha$, Diabetes, vol. 49 , no. 11 , pp. 1904-1909, 2000.

[169] M. A. Nimmo, M. Leggate, J. L. Viana, and J. A. King, "The effect of physical activity on mediators of inflammation," Diabetes, Obesity and Metabolism, vol. 15, no. 3, pp. 51-60, 2013.

[170] B. K. Pedersen and M. A. Febbraio, "Point: interleukin-6 does have a beneficial role in insulin sensitivity and glucose homeostasis," Journal of Applied Physiology, vol. 102, no. 2, pp. 814-816, 1985.

[171] F.-C. Hsu, S. B. Kritchevsky, Y. Liu et al., "Association between inflammatory components and physical function in the health, aging, and body composition study: a principal component analysis approach," Journals of Gerontology-Series A: Biological Sciences and Medical Sciences, vol. 64, no. 5, pp. 581-589, 2009.

[172] M. Hawkins, L. M. Belalcazar, K. B. Schelbert, C. Richardson, C. M. Ballantyne, and A. Kriska, "The effect of various intensities of physical activity and chronic inflammation in men and women by diabetes status in a national sample," Diabetes Research and Clinical Practice, vol. 97, no. 1, pp. e6-e8, 2012.

[173] K. D. Flack, K. P. Davy, M. W. Hulver, R. A. Winett, M. I. Frisard, and B. M. Davy, "Aging, resistance training, and diabetes prevention," Journal of Aging Research, vol. 2011, Article ID 127315, 12 pages, 2011.

[174] J. Yin, Z. Hao, Y. Ma et al., "Concomitant activation of the PI3K/Akt and ERK1/2 signalling is involved in cyclic compressive force-induced IL-6 secretion in MLO-Y4 cells," Cell Biology International, vol. 38, no. 5, pp. 591-598, 2014.

[175] T. H. Kim, S. E. Choi, E. S. Ha et al., "IL-6 induction of TLR-4 gene expression via STAT3 has an effect on insulin resistance in human skeletal muscle," Acta Diabetologica, vol. 50, no. 2, pp. 189-200, 2013.

[176] M. A. Febbraio, "Role of interleukins in obesity: implications for metabolic disease," Trends in Endocrinology and Metabolism, vol. 25, no. 6, pp. 312-319, 2014. 


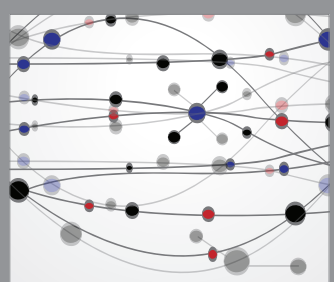

The Scientific World Journal
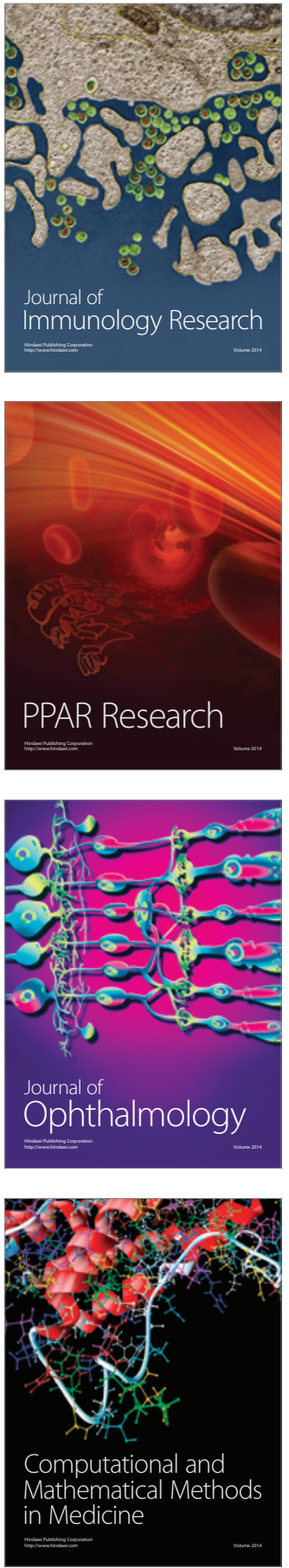

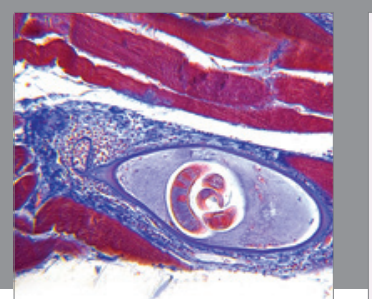

Gastroenterology Research and Practice

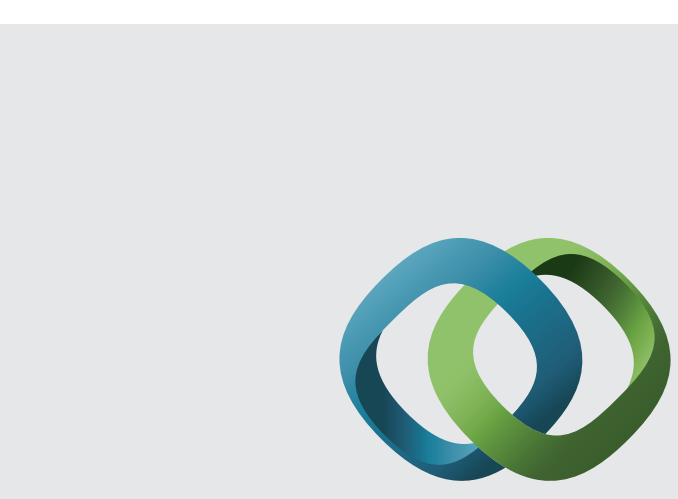

\section{Hindawi}

Submit your manuscripts at

http://www.hindawi.com
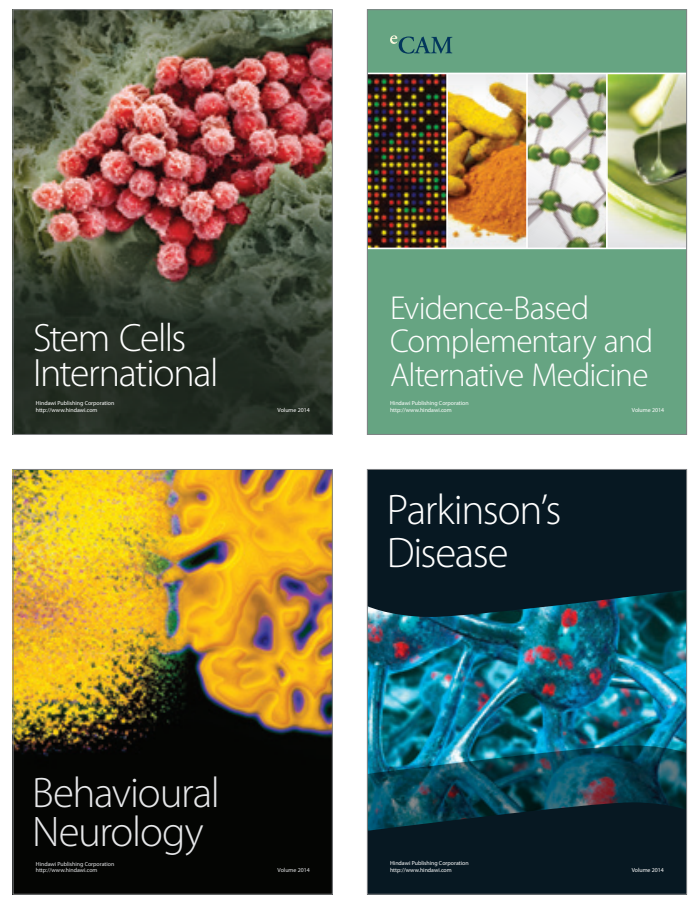
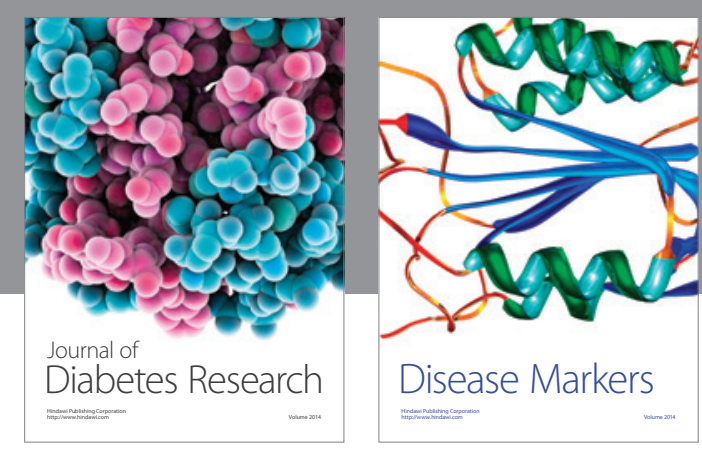

Disease Markers
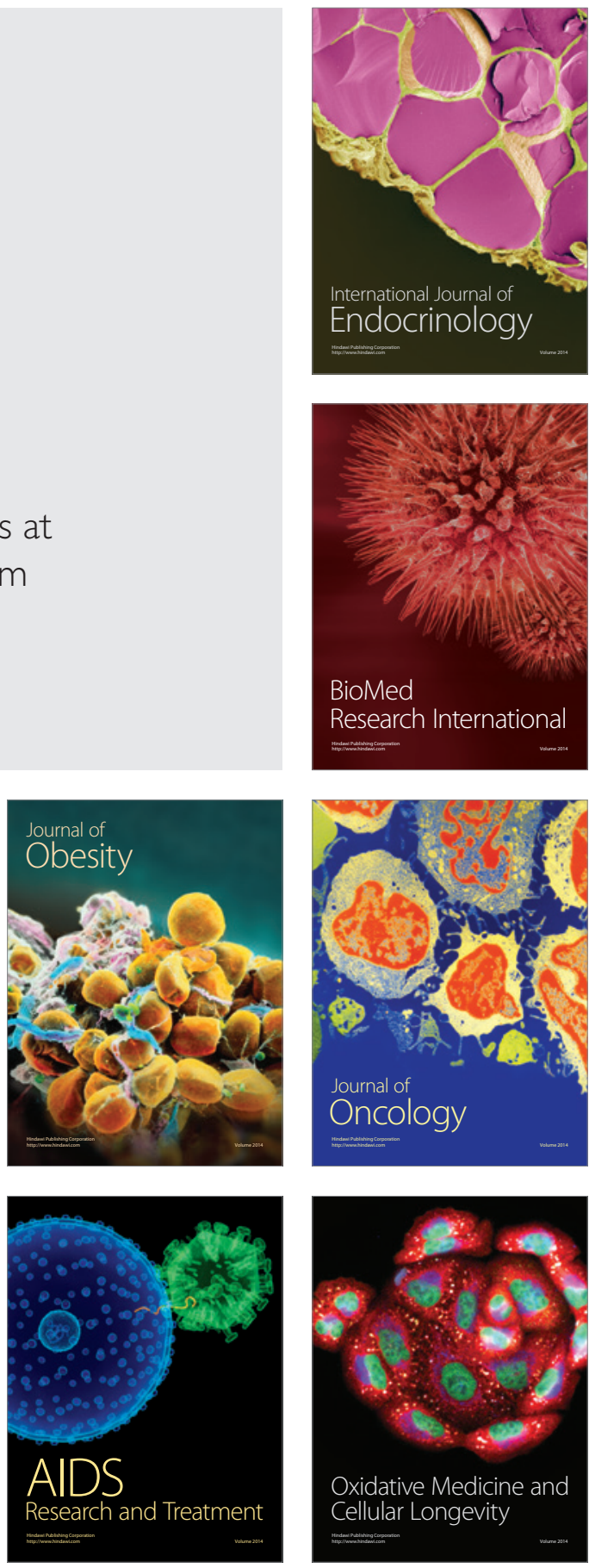